\title{
Energy flexibility for heating and cooling based on seasonal occupant thermal adaptation in mixed-mode residential buildings
}

Article

Accepted Version

Creative Commons: Attribution-Noncommercial-No Derivative Works 4.0

Du, C., Li, B., Yu, W., Liu, H. and Yao, R. (2019) Energy flexibility for heating and cooling based on seasonal occupant thermal adaptation in mixed-mode residential buildings.

Energy, 189. 116339. ISSN 0360-5442 doi: https://doi.org/10.1016/j.energy.2019.116339 Available at https://centaur.reading.ac.uk/87079/

It is advisable to refer to the publisher's version if you intend to cite from the work. See Guidance on citing.

To link to this article DOI: http://dx.doi.org/10.1016/j.energy.2019.116339

Publisher: Elsevier

All outputs in CentAUR are protected by Intellectual Property Rights law, including copyright law. Copyright and IPR is retained by the creators or other copyright holders. Terms and conditions for use of this material are defined in the End User Agreement. 


\section{CentAUR}

Central Archive at the University of Reading

Reading's research outputs online 
Energy $x x x(x x x x) x x x$

Energy flexibility for heating and cooling based on seasonal occupant thermal adaptation in mixed-mode residential buildings

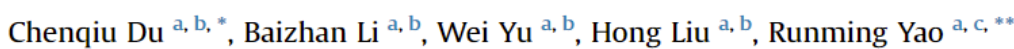

a Joint International Research Laboratory of Green Buildings and Built Environments, Ministry of Education, Chongqing University, Chongqing, 400045,

China

National Centre for International Research of Low-carbon and Green Buildings, Ministry of Science and Technology, Chongqing University, Chongqing

400045, China
'School of the Built Environment, University of Reading, Reading, RG6 6AW, UK

\title{
Title Page
}

\section{Title:}

Energy flexibility for heating and cooling based on seasonal occupant thermal adaptation in mixed-mode residential buildings

\section{Authors:}

Chenqiu Du ${ }^{a, b *}$, Baizhan $\mathrm{Li}^{a, b}$,Wei Yu ${ }^{a, b}$, Hong Liu ${ }^{a, b}$, Runming Yao ${ }^{a, c *}$

\author{
Affiliation: \\ a Joint International Research Laboratory of Green Buildings and Built Environments, \\ Ministry of Education, Chongqing University, Chongqing 400045, China \\ ${ }^{\mathrm{b}}$ National Centre for International Research of Low-carbon and Green Buildings, \\ Ministry of Science and Technology, Chongqing University, Chongqing 400045, \\ China \\ ${ }^{\mathrm{c}}$ School of the Built Environment, University of Reading, Reading RG6 6AW, UK \\ *Corresponding authors:
}

Email: duchenqiu90@163.com; r.yao@ reading.ac.uk 


\begin{abstract}
The energy flexibility for heating and cooling has not been fully explored though human thermal adaptation has been acknowledged in achieving energy savings in buildings. The aim of this study is to explore the capacity for heating/cooling flexibility in residential buildings in the hot summer and cold winter zone in China, by investigating the year-round dynamic changes in the thermal adaptation of occupants. A 13,005-set data set was extracted from a nation-wide field survey database. The results showed that the measured indoor temperatures were linearly related to the outdoor temperature in transient seasons but were discrete in the summer/winter seasons due to the mixed-mode operations of heating/cooling devices. The occupants' neutral temperatures varied with outdoor temperatures in step with seasonal changes. Flexibility of temperature settings during the whole heating and cooling periods have been demonstrated, incorporating the dynamic thermal adaptation changes of occupants; such implementation has been estimated with great energy saving potential (e.g. $34.4 \%$ in Nanjing). This work contributes to the quantitative understanding of the role of human thermal adaptation in the smart control of residential energy management. It provides evidence for policy-making for flexible thermal design codes in building, to discourage excessive cooling/heating demands.
\end{abstract}

Keywords: residential buildings; dynamic thermal adaptation; heating and cooling; temperature settings; energy flexibility. 


\section{Introduction}

According to China's National Bureau of Statistics [1], the hot summer and cold winter (HSCW) zone of China has the highest national population density (21\% of the urban residential population). It contains approximately 9 billion $\mathrm{m}^{2}$ of building stock, of which residential building accounts for $66 \%$ [2]. For residential buildings in the HSCW zone, in the absence of central heating systems, annual indoor thermal environments are linearly related to outdoor climates and fluctuate outside the comfort ranges defined by standards $[3,4]$. With the rapid economic growth and high rate of urbanisation in this region, energy demand for improving indoor thermal comfort has experienced considerable growth [5,6], for example, the electricity demand for heating has increased five-fold from 7.7 billion $\mathrm{kWh}$ in 2001 to 41.4 billion $\mathrm{kWh}$ in 2011 [2]. Nevertheless, the national targets pertaining to the cap on primary energy consumption and peak $\mathrm{CO}_{2}$ emissions [7] have placed specific pressure on this region's energy strategy. In such cases, researchers and policy-makers are seriously considering the trade-off between improving resident wellbeing and meeting building energy efficiency target in this region.

In the conventional design of indoor thermal environments in the HSCW zone, thermal comfort is set based on a constant or narrow range of temperature values for the heating and cooling periods $[8,9]$. Existing research revealed that residents in this region have long-established adaptations to the local climates, which modifies their expectations and extends their comfort zones for indoor thermal environments [10, 11]. In the HSCW zone, due to the typical hot summer, cold winter and mild spring/autumn characteristics, occupants in residential buildings use mixed-mode thermal control. The mixed-mode, by definition, is that occupants use a combination of natural ventilation from windows and rely on distributed mechanical systems (e.g. air conditioners, electric heaters) for cooling/heating in very hot or cold climates where relying on human adaption is a less efficient means of improving comfort [12]. Mixed-mode operation in office buildings has been previously studied [13-15], but these findings cannot be applied directly to residential buildings as residents are more able to adjust the thermal environment in their homes than in the workplace. To the best of our knowledge, few studies exist regarding the evaluation and operation of thermal comfort in mixed-model residential buildings. Some underexplored issues 
include: bridging the link between air-conditioned buildings and naturally ventilated buildings; evaluating the role of occupant thermal adaptations in mixed-mode buildings over the year; identifying the annual dynamic comfort demands of residents; and exploring the heating/cooling energy flexibilities by taking into account occupant thermal adaptations.

Although linear relationships have been confirmed between the outdoor temperature and indoor comfort temperature in naturally ventilated residential buildings, a more complex relationship occurs when outdoor temperatures are at high and low levels $[16,17]$. It is reported that occupants' thermal adaptations are dynamic [18] and are affected by climates, seasons, building characteristics, thermal experience and backgrounds linked to economic, cultural and social status, etc. These were incorporated and reflected by an adaptive coefficient $\lambda$, which was proposed by Yao et al. in the aPMV model [19]. In the light of this, Liu et al. [20] found that the neutral temperature of residents in the HSCW zone varied seasonally, with higher values in summer and lower ones in winter $\left(24.25^{\circ} \mathrm{C}\right.$ and $21.02^{\circ} \mathrm{C}$, respectively). Similarly, using a full-year monitoring of indoor temperature, thermal perception and windowopening behaviour in Japanese dwellings, Rijal et al. [21] found a significant seasonal difference in the comfort temperatures, which was correlated to both indoor and outdoor climates . Wang et al. [22] measured indoor temperatures over an entire heating season in a severe cold zone of China, and reported that the increasing use of heating in the middle heating period led to a gradual increase in perceived comfort temperatures. Even for the same thermal environment, the thermal experience of different seasons shaped the physiological regulation and thermal responses of occupants [23-25]. These variations in thermal comfort demands of people are believed to influence the heating/cooling designs in winter/summer seasons. However, research focus on transitional variations of human thermal adaptation from the point of view of the entire heating/cooling periods, along with the effect of changes in the adaptive process of occupants on comfort demands is not yet well described. Therefore, there is a research gap in incorporating human thermal adaptation and dynamic comfort demands within heating/cooling control in order to optimize the energy flexibility in mixed-mode residential buildings in this region.

Recently, the demand-response (DR) control of indoor temperature setting-points 
in buildings has attracted the interest of researchers, in both the indoor thermal environment and building energy efficiency fields. Aghniaey et al. [26] reviewed the impact of the DR on setting-point changes and occupant thermal comfort, highlighting the potential for energy saving during cooling seasons. Hong et al. [27] proposed a multi-objective optimization model and conducted seasonal analysis with a building design scenario; the study focused on changing temperature setting-points from spring to summer and from autumn to winter and minimized the energy consumption. Considering human thermal demands, Wu et al. [28] found $8 \%$ of cooling energy could be saved during summer when occupants were free to control the split air conditioner in office buildings. Zhang et al. [29] conducted a temperature-control experiment in a hot-humid area in summer; compared to a conventional thermostat setting of $26^{\circ} \mathrm{C}$. Increasing the indoor temperatures based on thermal adaptation of people resulted in a $31 \%$ and $40 \%$ reduction in the daily mean energy consumption of air conditioning on sunny and overcast days, respectively. However, these studies focused on the implementation of dynamic temperature settings for building energy savings. The theoretical analysis underlying the dynamic or adaptation-based regulation for indoor thermal environments has yet to be fully addressed. In addition, how human thermal adaptation is reflected in DR-based control and energy flexibility remains underexplored.

Taken together, a holistic understanding of the temporal and spatial variations of human thermal adaptation according to climate and season is critical in order to incorporate thermal adaptation into building heating/cooling operation appropriately. To this end, this study extracted data relating to the HSCW zone from a database that was formed from a nation-wide field survey in China, and attempted to explore the regulation of the dynamic adaptive changes made by occupants in mixed-mode residential buildings, especially in cooling/heating seasons. The study further quantified the thermal adaptation of occupants by analysing the neutral temperature variations over a year in order to provide a reference for the determination of design temperatures. A method for dynamically controlling temperature setting-points in the early, middle, and late summer and winter seasons had been proposed and consequently the resulting energy saving was estimated. The work reveals and quantifies the dynamic heating/cooling temperature settings in mixed-mode 
residential buildings and contributes to the guidance for energy-flexible system operations for heating and cooling.

\section{Methods}

\subsection{Information from the database}

This study is based on a 20,000-record database obtained via a national field survey in China collected in the five different climate zones over a period of four years (2008-2011). The surveys were conducted in different residential buildings in each city. The subjective perception evaluations of residents for the indoor thermal environments at that time were investigated. Meantime, the environmental parameters of indoor temperature, relative humidity and air velocity were measured, complying with ISO 7726 [30]; all measurements were repeated outdoors close to the surveyed building in locations protected from direct sunlight. Detailed descriptions of the surveys, questionnaires and measurements are available in Ref. [4, 20, 31].

\subsection{Data screening}

Six provincial capital cities, i.e. Chengdu, Chongqing, Changsha, Wuhan, Nanjing and Hangzhou in this zone were extracted from the database in order to focus on the HSCW region. The basic geographic information and annual meteorological data for the six cities are summarized in Table 1 [32]. From Table 1, the six cities have similar longitudes and slight fluctuations in annual mean air temperature $\left(15.4-18.5^{\circ} \mathrm{C}\right)$ and relative humidity (74.9-82.2\%) respectively, which reflects the typical climate characteristics in the HSCW zone.

Table 1: Geographic information and typical meteorological data of the six cities

\begin{tabular}{llllllll}
\hline City & Latitude & Longitude & Altitude(m) & $\begin{array}{l}\text { Annual average } \\
\text { temp }\left({ }^{\circ} \mathrm{C}\right)\end{array}$ & $\begin{array}{l}\text { Annual average } \\
\mathrm{RH}(\%)\end{array}$ & $\begin{array}{l}\text { Annual average } \\
\text { radiation(W/m2) }\end{array}$ & $\begin{array}{l}\text { Annual average } \\
\text { outdoor wind(m/s) }\end{array}$ \\
\hline Chengdu & 103.5 & 30.5 & 547.7 & 16.6 & 81.0 & 101.2 & 1.2 \\
Chongqing & 106.3 & 29.4 & 259.1 & 18.5 & 81.5 & 98.5 & 1.5 \\
Changsha & 112.6 & 28.1 & 68.0 & 17.1 & 82.2 & 125.4 & 2.2 \\
Wuhan & 114.4 & 30.4 & 23.6 & 16.5 & 75.7 & 136.8 & 1.5 \\
Nanjing & 118.5 & 31.6 & 35.2 & 15.4 & 74.9 & 145.7 & 2.5 \\
Hangzhou & 120.1 & 30.1 & 41.7 & 17.0 & 75.8 & 140.2 & 2.1 \\
\hline
\end{tabular}


Based on the above-mentioned database in Section 2.1, 13,005 sets of valid data for mixed-mode residential buildings were extracted and screened, including 2,363 for Chengdu, 2,151 for Chongqing, 1,601 for Changsha, 2,369 for Wuhan, 2,639 for Nanjing and 1,882 for Hangzhou. For the survey, residents were free to change their clothes, use windows for ventilation, or operate heating/cooling devices when the indoor thermal environment was out of their comfort zone. All these were recorded in the questionnaire (see the Appendix of Ref.[4]). When pooling data, we regarded these employments of local devices at the time of investigation as individual regulatory behaviours to adapt to environments; these cases were included in samples in each city. Table 2 summarizes the devices used by residents and the corresponding numbers of cases in each city. It is seen that various heating/cooling devices were used in residential buildings in summer and winter. Split air conditioners and fans formed the majority of devices used by residents, accounting for $47.6 \%$ (1,269 cases) and 35.1\% (936 cases) respectively. In addition, the total number of cases where heating/cooling devices were employed was up to 550 in Changsha and 977 in Wuhan - about $34.4 \%$ and $41.2 \%$ of the total samples in these two cities. Given that these regulatory behaviours would affect the indoor temperatures and the comfort ranges of residents, all these cases were included and correlated to their thermal sensation evaluations in the analysis.

Table 2: Samples using various heating/cooling devices at the time of the survey

\begin{tabular}{|c|c|c|c|c|c|c|c|c|c|c|}
\hline \multirow[b]{2}{*}{ Cities } & \multicolumn{10}{|c|}{ Devices used in investigated buildings } \\
\hline & $\begin{array}{l}\text { Split air } \\
\text { conditioner }\end{array}$ & Fan & $\begin{array}{l}\text { Window air } \\
\text { conditioner }\end{array}$ & $\begin{array}{l}\text { Air } \\
\text { conditioning } \\
\text { unit }\end{array}$ & $\begin{array}{l}\text { Central } \\
\text { cooling }\end{array}$ & $\begin{array}{l}\text { Central } \\
\text { heating }\end{array}$ & $\begin{array}{l}\text { Warm } \\
\text { air } \\
\text { blower }\end{array}$ & $\begin{array}{l}\text { Electric } \\
\text { heater }\end{array}$ & $\begin{array}{l}\text { Electric } \\
\text { stove }\end{array}$ & Total \\
\hline Chengdu & 35 & 101 & 5 & 0 & 0 & 0 & 5 & 5 & 2 & 153 \\
\hline Chongqing & 64 & 106 & 4 & 2 & 0 & 0 & 2 & 5 & 2 & 185 \\
\hline Changsha & 363 & 138 & 4 & 5 & 0 & 0 & 1 & 4 & 35 & 550 \\
\hline Wuhan & 386 & 265 & 84 & 21 & 44 & 40 & 123 & 0 & 14 & 977 \\
\hline Nanjing & 250 & 192 & 5 & 21 & 0 & 1 & 2 & 0 & 1 & 472 \\
\hline Hangzhou & 171 & 134 & 21 & 3 & 0 & 1 & 0 & 0 & 0 & 330 \\
\hline Total & 1269 & 936 & 123 & 52 & 44 & 42 & 133 & 14 & 54 & 2667 \\
\hline
\end{tabular}




\subsection{Statistical analysis}

In data analysis, the measured indoor and outdoor temperatures were used to match the occupants' thermal responses during different seasons. Since the measured air temperatures were continuous variables, while the subjective variables from residents were categorical variables, it was difficult to observe the change laws between both using raw data and larger sample sizes. Therefore, we adopted the Bin method for data discretization [33] and distributed the temperature values over limited temperature intervals. Coupled with the basic analyses that have been presented [4, 20], the Bin method in this study enables us to reflect fully the characteristics and relationships between independent variables and dependent variables. Therefore, the temperature intervals were used to average the variables at each temperature interval in Sections 3.3-3.5. In addition, we assumed that the mean radiant temperature in investigated buildings was equal to the air temperature, since there were no obvious radiant sources or radiant heating/cooling systems (Table 2). Thus, the indoor operative temperature was assumed to be equal to the air temperature and was used to calculate the neutral temperatures of residents in Section 3.5. Moreover, the hourly dry-bulb temperatures for the six cities based on a typical meteorological year (TMY) were employed, using weather data from EnergyPlus software (https://www.energyplus.net/weather). Such typical meteorological data, which are commonly used for building design and energy simulations, are adopted in Sections 3.6 and 3.7 as a benchmark for the outdoor climate in which the indoor thermal environment operates.

Clothing regulation is one of the most effective ways for occupants to respond to temperature changes in winter. We first translated the overall garment in questionnaires into a CLO value according to ISO 9920 [34], and the total clothing insulation was obtained by adding the values of all the garments worn by the occupants. When analysing the changes of occupants' clothing insulation as a function of indoor temperature, the data were divided into three groups: early winter (November), mid-winter (December and January) and late winter (February), and binned into one-degree increments in each group to average the clothing insulation values. The same method was used for indoor air velocity in summer, based on the data from three summer periods: early summer (June), mid-summer (July and 
August), and later summer (September).

The Probit model (Eq. (1)) is commonly used to describe the probability of a certain behaviour under the influence of different factors; this was used in this study as Eq. (2), to describe the changes in the occupants' thermal expectations of desiring warmer or cooler temperatures at each temperature interval. The proportion was regarded as a function of indoor temperature and regressions were conducted using Origin 9.0 software.

$$
\begin{gathered}
\mathrm{P}\left(\mathrm{y}_{\mathrm{i}}=1 \mid \mathrm{x}_{\mathrm{i}}\right)=1 /\left[1+\mathrm{e}^{-\left(\alpha+\beta \mathrm{x}_{\mathrm{i}}\right)}\right] \\
\mathrm{P}=(\exp (\mathrm{a}+\mathrm{bT})) /(1+\exp (\mathrm{a}+\mathrm{bT}))
\end{gathered}
$$

Here, $\mathrm{P}$ is the percentage of occupants desiring warmer/cooler temperatures (\%), $\mathrm{T}$ is the indoor temperature $\left({ }^{\circ} \mathrm{C}\right)$, and $\mathrm{a}$ and $\mathrm{b}$ are the regression coefficients.

\section{Results}

\subsection{Descriptive statistical analysis of the questionnaire data for the six cities}

The information on the investigated buildings is summarized in Table 3. Except for Nanjing, where most of the buildings were built before the 1990s (56.7\%) and in the 1990s (41.1\%), the investigated buildings in the other four cities were built in the 1990s and after 2000. In Chengdu, 93.1\% of the surveyed buildings were reinforced concrete structures, with 59\% being high-rise buildings (7-20 floors). In contrast, $97 \%$ of the buildings were brick-concrete structures in Hangzhou, and $84.4 \%$ of these had less than six floors. It is noted that in the HSCW zone, unlike northern China, due to the climate characteristics and lack of central heating, a higher proportion of buildings has single-frame-single-glass windows, with $98.5 \%$ in Chengdu, $92.4 \%$ in Chongqing, $94.1 \%$ in Changsha, $81.9 \%$ in Nanjing and 92.6\% in Hangzhou. In Wuhan, since $62.8 \%$ of the investigated buildings were built after 2000, two-thirds of the windows were single-frame-double-glass and double-frame-double-glass types.

Table 3: Detailed information on the investigated buildings in the five cities.

\begin{tabular}{cccccccc}
\hline Parameters & Category & Chengdu & Chongqing & Changsha & Wuhan & Nanjing & Hangzhou \\
\hline \multirow{2}{*}{$\begin{array}{c}\text { Construction } \\
\text { ages }\end{array}$} & Total cases* & 2276 & 2023 & 1561 & 2303 & 2540 & 1809 \\
Before the '90s (\%) & 6.3 & 6.5 & 36.7 & 18.3 & 56.7 & 14
\end{tabular}




\begin{tabular}{cccccccc} 
& In the '90s (\%) & 76.4 & 20.2 & 40.8 & 18.9 & 42.1 & 19.4 \\
& After the '90s (\%) & 17.3 & 73.3 & 22.5 & 62.8 & 1.3 & 66.6 \\
\hline \multirow{3}{*}{$\begin{array}{c}\text { Tonstruction } \\
\text { types }\end{array}$} & $\begin{array}{c}\text { Trick-concrete (\%) } \\
\text { Reinforced concrete }\end{array}$ & 6.6 & 78.9 & 54.1 & 78.4 & 59 & 1881 \\
& $(\%)$ & 93.1 & 21.1 & 45.1 & 20 & 41 & 3
\end{tabular}

\begin{tabular}{|c|c|c|c|c|c|c|c|}
\hline & Other $(\%)$ & 0.3 & 0 & 0.8 & 1.6 & 0 & 0 \\
\hline \multirow{4}{*}{ Floors } & Total cases $*$ & 2359 & 2102 & 1601 & 2349 & 2636 & 1881 \\
\hline & $\leq 6(\%)$ & 41 & 8 & 61.6 & 53.1 & 53.6 & 84.4 \\
\hline & $7--20(\%)$ & 59 & 69 & 35.9 & 34.8 & 45.6 & 15.6 \\
\hline & $\geq 21(\%)$ & 0 & 23 & 2.5 & 12.1 & 0.8 & 26.9 \\
\hline \multirow{4}{*}{ Room types } & Total cases* & 2360 & 2147 & 1539 & 2343 & 2636 & 1824 \\
\hline & $\leq 2$ bedrooms $(\%)$ & 28 & 40.5 & 30.8 & 23.6 & 74 & 56.3 \\
\hline & 3 bedrooms (\%) & 62.00 & 53 & 66 & 62.3 & 25.7 & 16.8 \\
\hline & $\geq 4$ bedrooms $(\%)$ & 10 & 6.5 & 3.2 & 13.1 & 0.3 & 0 \\
\hline \multirow{4}{*}{ Window types } & Total cases* & 2319 & 2055 & 1551 & 2217 & 2524 & 1847 \\
\hline & $\begin{array}{c}\text { Single-frame-single-glass } \\
(\%)\end{array}$ & 98.5 & 92.4 & 94.1 & 35.1 & 81.9 & 92.6 \\
\hline & $\begin{array}{c}\text { Single-frame-double-glass } \\
(\%)\end{array}$ & 1 & 6.2 & $4 \%$ & 31.2 & 17.1 & 6 \\
\hline & $\begin{array}{c}\text { Double-frame-double- } \\
\text { glass }(\%)\end{array}$ & 0.5 & 1.4 & 1.9 & 33.7 & 0.1 & 1.4 \\
\hline
\end{tabular}

Notes: * Since some residents did not answer all the questions in the questionnaire, the total cases counted in Table 3 was slightly less than the sample size given in Section 2.2 for each city.

Table 4 lists the basic information for residents in the investigated households, covering ages, gender, occupation, home stay durations and the number of residents at the time of the survey. The numbers of male and female residents investigated were approximately equal, ensuring the samples were representative. In addition, the proportion of residents answering that they usually stay at home for more than 10 hours ranged from $65.7 \%$ in Chongqing to $80.5 \%$ in Nanjing. This reflects the typical activity and occupancy situations of residents, which is believed to affect their behaviours and energy use at home.

Table 4: Background information on the residents in the five cities.

\begin{tabular}{cccccccc}
\hline Parameters & Category & Chengdu & Chongqing & Changsha & Wuhan & Nanjing & Hangzhou \\
\hline Gender & Total cases* & 2358 & 2114 & 1420 & 2127 & 2625 & 1871
\end{tabular}




\begin{tabular}{|c|c|c|c|c|c|c|c|}
\hline & Female (\%) & 52.2 & $56.1 \%$ & $52.4 \%$ & $49.5 \%$ & $48.8 \%$ & $58.4 \%$ \\
\hline & Male (\%) & 47.8 & $43.9 \%$ & $47.6 \%$ & $50.5 \%$ & $51.2 \%$ & $41.6 \%$ \\
\hline \multirow{4}{*}{ Ages } & Total cases & 2330 & 2115 & 1406 & 2122 & 2607 & 1882 \\
\hline & $<20(\%)$ & 0.3 & $5.9 \%$ & $3.8 \%$ & $12.5 \%$ & $1.3 \%$ & $0.5 \%$ \\
\hline & $20-60(\%)$ & 93.7 & $76.4 \%$ & $75.4 \%$ & $86.2 \%$ & $94.1 \%$ & $98.7 \%$ \\
\hline & $>60(\%)$ & 6 & $17.7 \%$ & $20.8 \%$ & $1.3 \%$ & $4.6 \%$ & $0.8 \%$ \\
\hline \multirow{4}{*}{ Occupation } & Total cases & 2226 & 1997 & 1491 & 1992 & 1860 & 1772 \\
\hline & $\begin{array}{l}\text { Government, } \\
\text { institution, company, } \\
\text { state organization (\%) }\end{array}$ & 72.9 & 47.1 & 47.6 & 53.2 & 50.7 & 43 \\
\hline & Technical staff (\%) & 10.8 & 26 & 32.6 & 43.8 & 35.5 & 55.7 \\
\hline & Others $(\%)$ & 16.3 & 26.9 & 19.8 & 3 & 13.6 & 1.3 \\
\hline \multirow{4}{*}{$\begin{array}{l}\text { Home stay time } \\
\text { (hours) }\end{array}$} & Total cases & 2295 & 2150 & 1514 & 2057 & 2125 & 1716 \\
\hline & $<1(\%)$ & 1.6 & 4.1 & 3.2 & 0.8 & 0.7 & 2.5 \\
\hline & $1-10(\%)$ & 27.2 & 30.2 & 29.9 & 18.8 & 18.8 & 20.7 \\
\hline & $>10(\%)$ & 71.2 & 65.7 & 66.9 & 80.4 & 80.5 & 76.8 \\
\hline \multirow{6}{*}{$\begin{array}{l}\text { Resident numbers at } \\
\text { the investigated } \\
\text { time }\end{array}$} & Total cases & 1999 & 2132 & 1565 & 1850 & 2143 & 1583 \\
\hline & $1(\%)$ & 22.6 & 24.8 & 23 & 34 & 33.1 & 14.7 \\
\hline & $2(\%)$ & 42 & 46.4 & 50.9 & 48.2 & 48.8 & 63.5 \\
\hline & $3(\%)$ & 27.9 & 16 & 17.7 & 13.6 & 15.8 & 16.4 \\
\hline & $4(\%)$ & 6.5 & 6 & 6.2 & 2.5 & 1.2 & 3.9 \\
\hline & $>4(\%)$ & 1.2 & 6.8 & 2.2 & 1.7 & 1.1 & 1.5 \\
\hline
\end{tabular}

Notes: * Similarly, as some residents did not answer the corresponding questions in the questionnaire, the total number of cases was slightly less than the sample size given in Section 2.2.

\subsection{Indoor and outdoor thermal environments}

Figure 1 exhibits the relations between indoor and outdoor air temperatures for the six cities, using the raw data measurements. From Figure 1, the indoor temperatures were significantly affected by the outdoor climates in the studied residential buildings in all six cities, when the outdoor temperatures were in the moderate range, e.g. $10-30^{\circ} \mathrm{C}$. This was in agreement with a study of naturally ventilated buildings [4, 35-37], where the indoor temperature was linearly related to outdoor temperature. However, as shown in Figure 1, when the outdoor temperature was below $10^{\circ} \mathrm{C}$, the indoor temperature increased, and when the outdoor temperature was above $30^{\circ} \mathrm{C}$, the indoor temperature decreased, in particular for Wuhan and 
Changsha. This was attributed to the operation of heating/cooling devices that improved the indoor temperatures. The observed outdoor temperature boundaries for employing heating /cooling are around $10-30{ }^{\circ} \mathrm{C}$, indicating the regulatory demands of residents for thermal comfort is linked to the outdoor climate at the time of the survey.
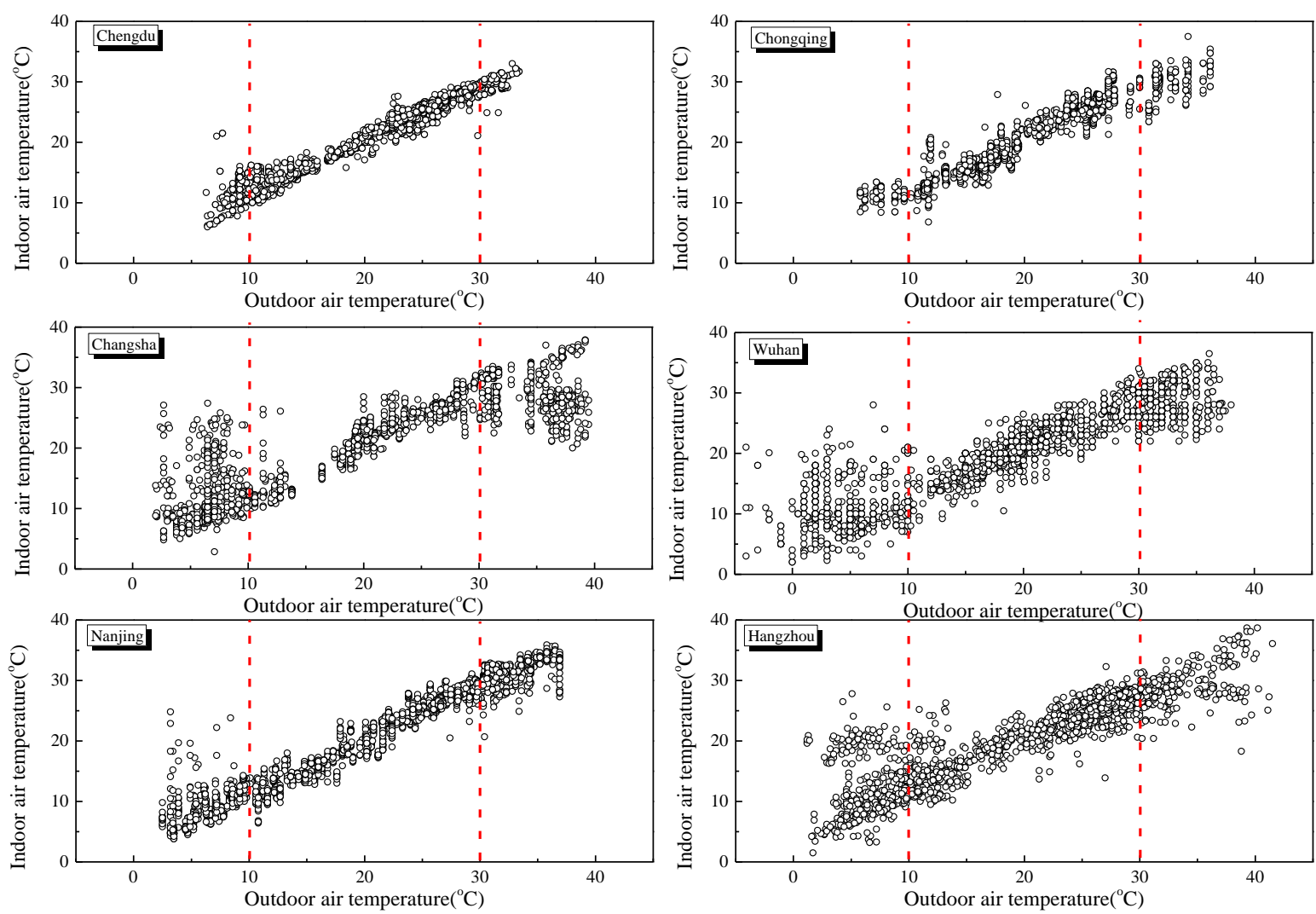

Figure 1: Relations between measured indoor and outdoor temperatures in the mixed-mode residential buildings of the six cities

\subsection{Expected temperature variations with annual temperature}

Human thermal preference is a more appropriate indicator of optimal thermal conditions than the universal thermal sensation [38]. In this study, in order to identify changes in the occupants' psychological thermal expectation over the year, we used the fractions of occupants desiring higher or lower temperatures (or no changes), as shown in Figure 2. The red squares represent the proportions where occupants expected to increase temperatures at that time; the blue circles represent the 
proportions expecting to decrease temperatures; the cyan dots are the proportions preferring no change. Similar trends of upper and lower temperature expectations were observed for all six cities, i.e. with increasing temperature, the proportion of occupants desiring a higher temperature decreased, while the number of those desiring a lower temperature increased. The Probit model regression was conducted for each city and the fitting curves are shown in Figure 2. The regression coefficients from the models and statistical tests are shown in Table 5. The regression models showed statistical significance, indicating that the occupants' thermal expectations were significantly affected by annual temperature variations.
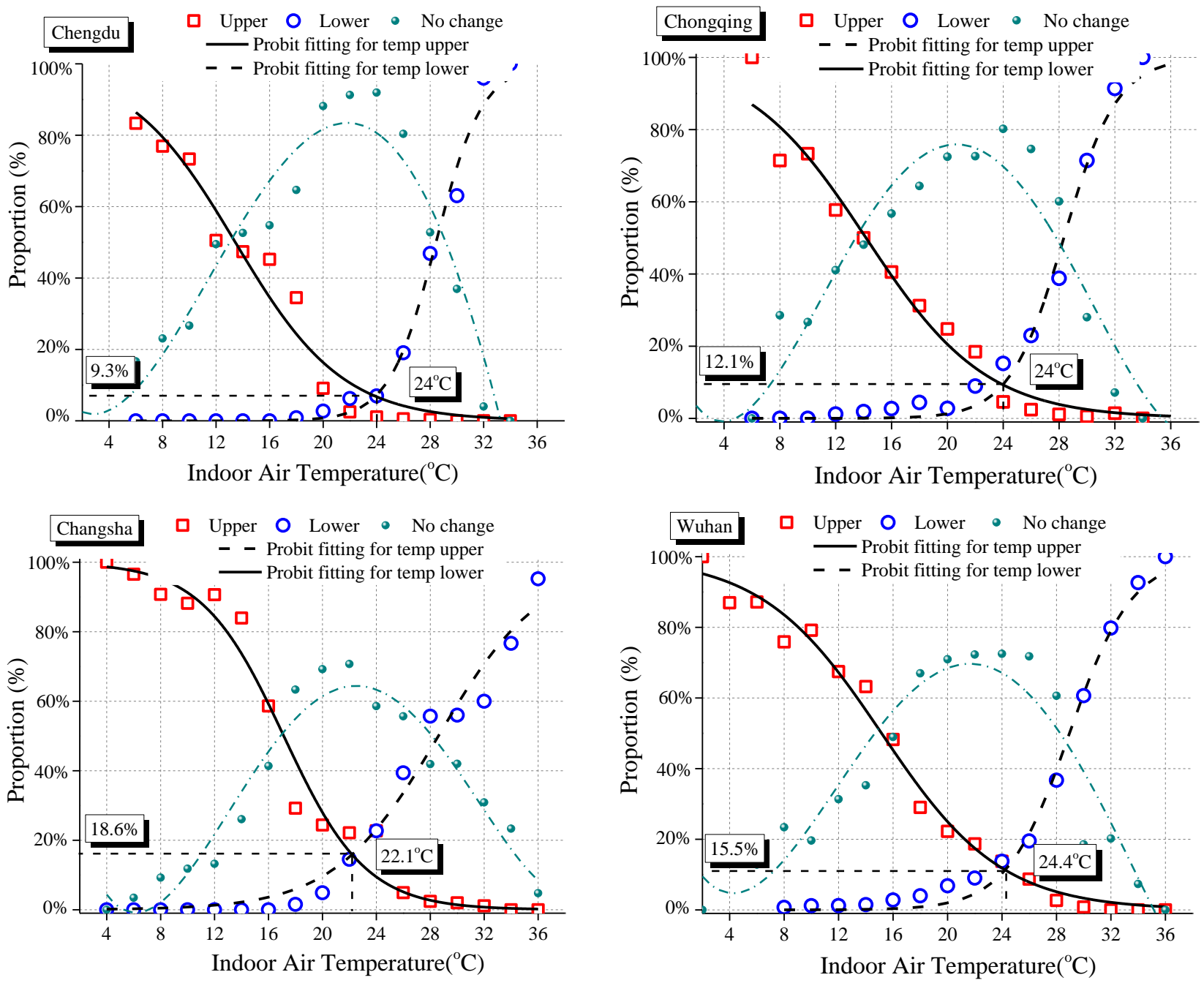

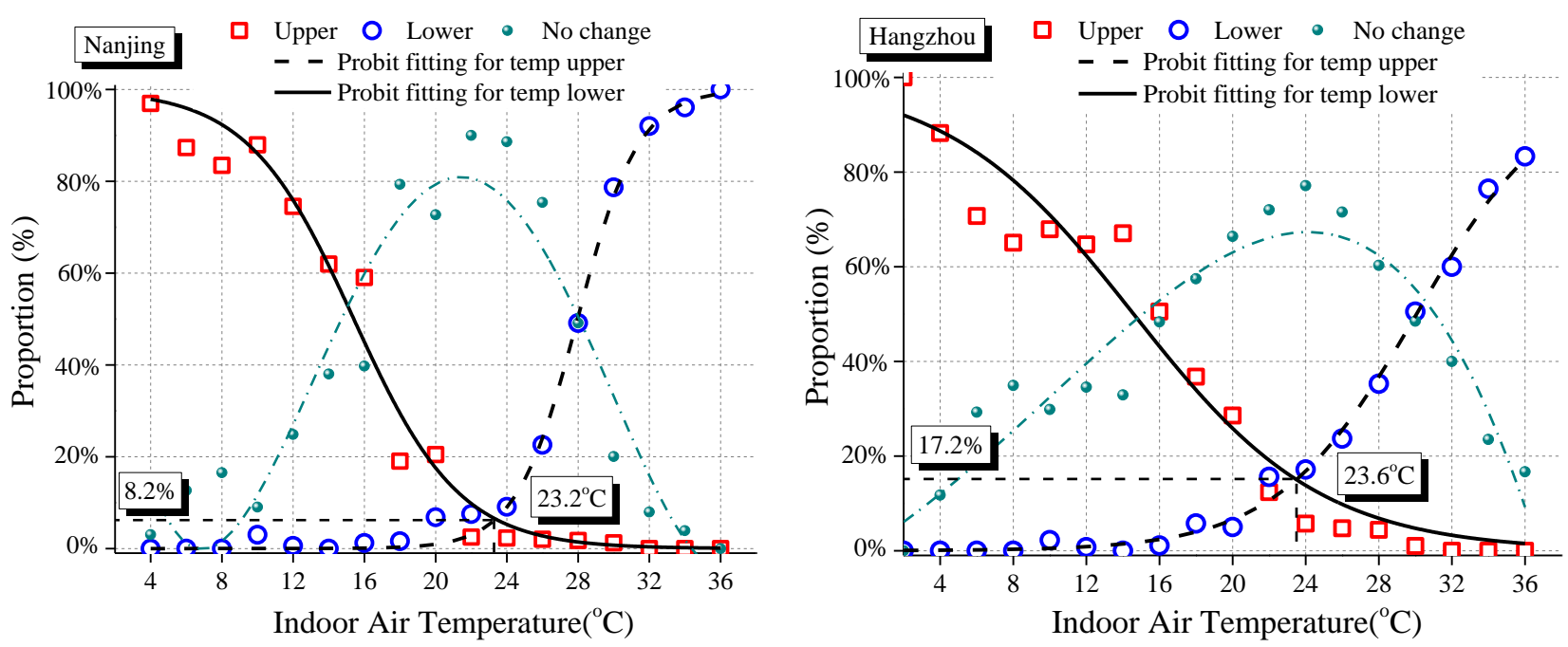

Figure 2: Proportion of occupant temperature preferences as a function of indoor air temperature for the six studied cities.

Table 5: Regression coefficients from the Probit models for the six cities using Equation (2)

\begin{tabular}{|c|c|c|c|c|c|c|c|c|c|c|c|c|}
\hline \multirow{2}{*}{ Coefficients } & \multicolumn{2}{|c|}{ Chengdu } & \multicolumn{2}{|c|}{ Chongqing } & \multicolumn{2}{|c|}{ Changsha } & \multicolumn{2}{|l|}{ Wuhan } & \multicolumn{2}{|c|}{ Nanjing } & \multicolumn{2}{|c|}{ Hangzhou } \\
\hline & $\mathrm{U}^{*}$ & $\mathrm{~L}^{* *}$ & $\mathrm{U}$ & $\mathrm{L}$ & $\mathrm{U}$ & $\mathrm{L}$ & $\mathrm{U}$ & $\mathrm{L}$ & $\mathrm{U}$ & $\mathrm{L}$ & $\mathrm{U}$ & $\mathrm{L}$ \\
\hline Samples & 16 & 18 & 17 & 18 & 18 & 16 & 18 & 18 & 18 & 17 & 18 & 18 \\
\hline$a^{* * *}$ & 3.34 & -16.38 & 5.64 & .7 .45 & 3.29 & -14.79 & 3.44 & -12.63 & 5.18 & -16.32 & 2.84 & -7.93 \\
\hline SD & 0.37 & 1.36 & 0.62 & & 0.29 & 1.19 & 0.21 & 0.77 & 0.56 & 0.87 & 0.32 & 0.64 \\
\hline $\mathrm{b}^{* * *}$ & -0.25 & 0.58 & -0.33 & 0.26 & -0.23 & 0.52 & -0.23 & 0.44 & -0.34 & 0.58 & -0.19 & 0.26 \\
\hline SD & 0.03 & 0.04 & 0.03 & & 0.02 & 0.04 & 0.01 & 0.02 & 0.03 & 0.03 & 0.02 & 0.02 \\
\hline Model $\mathrm{R}^{2}$ & 0.96 & 0.99 & 0.98 & 0.97 & 0.97 & 0.99 & 0.99 & 0.99 & 0.98 & 0.99 & 0.95 & 0.99 \\
\hline$F$ value & 346.26 & 1021.32 & 720.44 & 513.58 & 557.78 & 1345.18 & 1648.63 & 1706.85 & 628.21 & 3548.03 & 403.94 & 3011.4 \\
\hline Prob $>F$ & 0.00 & 0.00 & 0.00 & 0.00 & 0.00 & 0.00 & 0 & 0.00 & 0.00 & 0 & 0.00 & 0 \\
\hline
\end{tabular}

$\mathrm{U}^{*}$ : wanting temperature upper;

$\mathrm{L}^{* *}$ : wanting temperature lower.

a,b***: regression coefficients of model in Eq. (2).

According to Figure 2, the proportions wanting no temperature change increased gradually with increasing indoor temperature; but decreased when the indoor temperature exceeded certain values, indicating a significant effect of indoor temperature on occupants' thermal comfort. We defined the expected temperature as the indoor temperature corresponding to the intersection of the two fitted Probit curves $[38,39]$, where the percentages of occupants wanting warmer and cooler conditions were equal, and the percentage of occupants wanting no change was the highest. From the models, the expected temperatures for the six cities were $24.0^{\circ} \mathrm{C}$ for 
Chengdu and Chongqing, $22.1^{\circ} \mathrm{C}$ for Changsha, $24.1^{\circ} \mathrm{C}$ for Wuhan, $23.2^{\circ} \mathrm{C}$ for

Nanjing, and $23.6^{\circ} \mathrm{C}$ for Hangzhou over the whole year. These expected values can be used as general references for effectively controlling heating/cooling usage, especially in the transient periods from spring to summer and from autumn to winter.

\subsection{Behavioural adaptations in different periods of winter/summer seasons}

The most common behavioural adaptations to different indoor temperatures are choosing suitable clothes and increasing air movement [40]. However, as the level of adaptation changed in different periods of winter and summer, different preferences for clothing insulation and air velocity were observed, even for the same temperature conditions. This issue is discussed in more detail in the following sections.

\subsubsection{Clothing insulation and indoor temperature}

Previous studies of occupant clothing adjustment behaviours have shown a linear relationship between clothing insulation and outdoor temperature in the adaptive zone (e.g. $13^{\circ} \mathrm{C}$ and $25^{\circ} \mathrm{C}$ [41]), but using the large time scale of a year may overlook deviations caused by different thermal experiences responding to seasonal and local climates. Considering that clothing adjustment was limited for summer temperatures, we subdivided the time intervals by the early-, mid-, and late-winter periods and mainly focused on the dynamic variations of occupants' clothing insulation during the winter season. Given that the occupants were directly exposed to the indoor temperature, the indoor temperature index was used and the clothing insulation values were averaged over $1^{\circ} \mathrm{C}$ intervals for each city.

Figure 3 shows temporal variations in occupant clothing insulation with temperature for the three winter periods in different cities; major differences in clothing insulation were observed for the different periods, even for similar temperatures. In early winter, the clothing insulation values increased gradually as temperature decreased from over $20^{\circ} \mathrm{C}$ to approximately $10^{\circ} \mathrm{C}$, but remained lower than those for the other two periods for all six cities. This was attributed to the previous warm thermal experience of the outdoor climate in autumn, where physiological adaptations after long-term exposure to warmer environments enhanced tolerance for colder environments to some degree. In particular, clothing insulation 
was higher in Changsha $\left(>1.0\right.$ clo for temperatures below $\left.22^{\circ} \mathrm{C}\right)$, reflecting adaptation differences caused by local climates. In mid-winter, clothing insulation was the highest in all six cities; the values were within the range of 1.4-1.6clo and changed only slightly with temperature. It was inferred that after exposure to cold outdoor climates, the occupants wear more clothes to meet their comfort demands. However, in late winter, with the outdoor temperatures increasing again, the preferred clothing insulation level began to decrease. This trend was more significant in Nanjing, which exhibited a reduction from $1.4 \mathrm{clo}$ to $\sim 0.8 \mathrm{clo}$ as the temperature increased from $3^{\circ} \mathrm{C}$ to $17^{\circ} \mathrm{C}$. These results reveal directly the dynamic clothing adaptation according to outdoor climates and the occupants' experience of the temperature, which is thought to affect their thermal comfort demands.
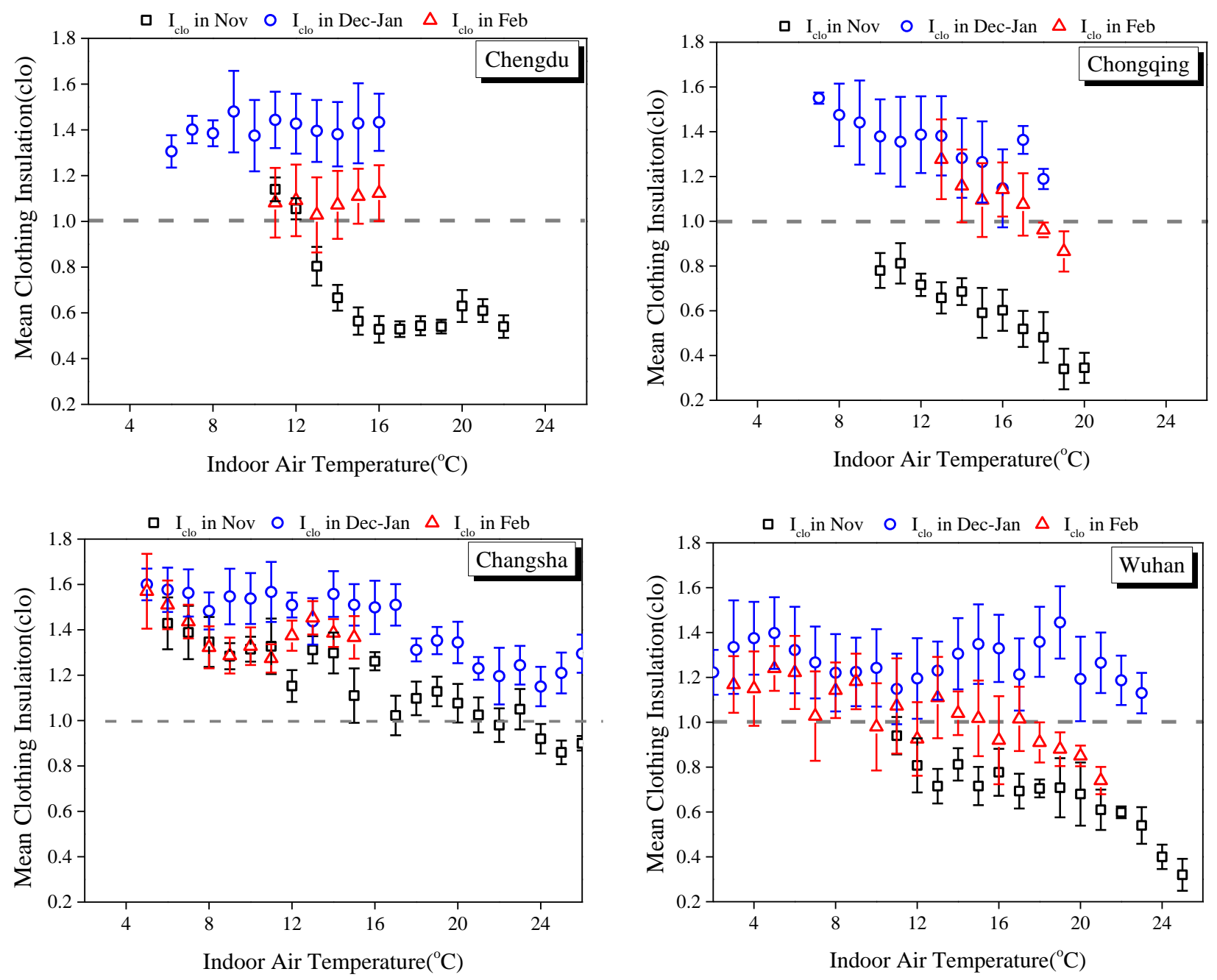

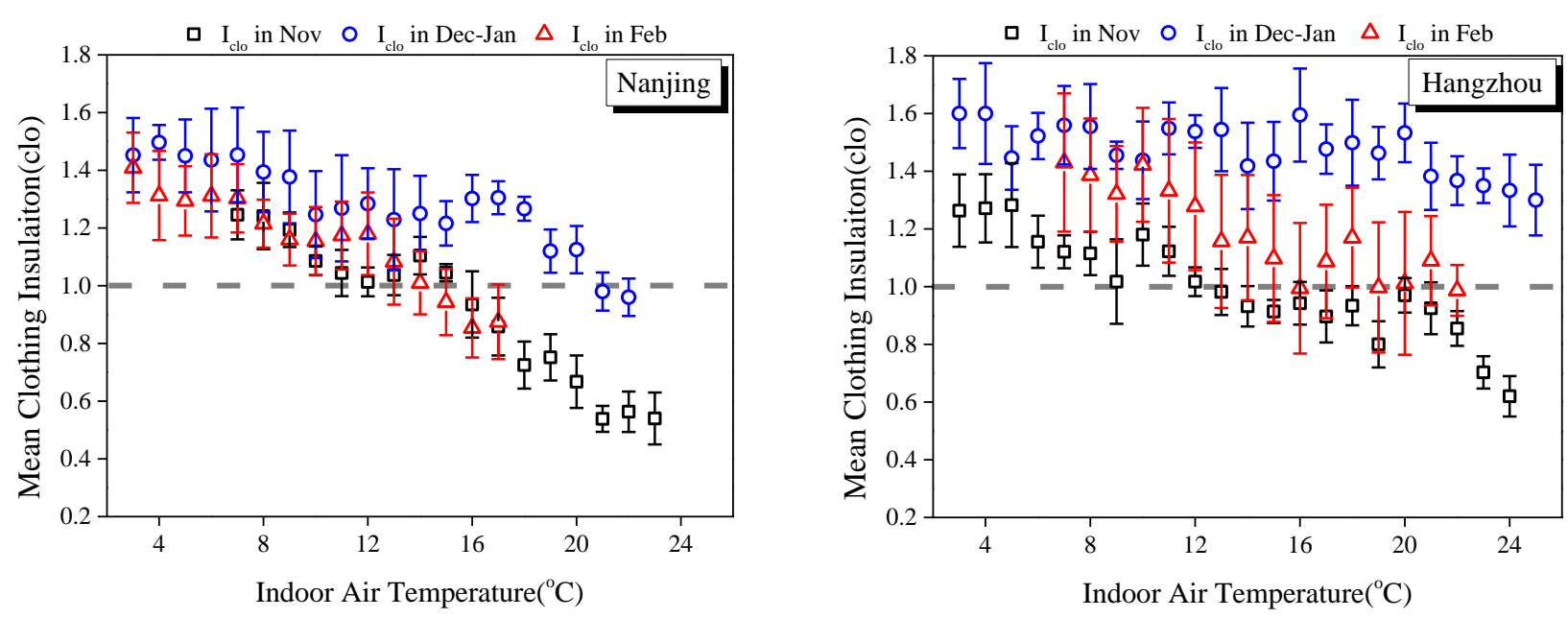

Figure 3: Occupant clothing insulation $\left(\mathrm{I}_{\text {clo }}\right)$ as a function of indoor temperature in different periods of winter (Nov $=$ early winter, Dec-Jan $=$ mid-winter, Feb $=$ late winter).

\subsubsection{Indoor air velocity and temperature}

As a common behavioural adaptation, opening windows and using fans occurred in warmer periods, accounting for a relatively high proportion (Table 4). Here, we explored changes of indoor air velocity in the early-, mid- and late-summer periods, as shown in Figure 4. The indoor temperature increased from $\sim 20^{\circ} \mathrm{C}$ to over $30^{\circ} \mathrm{C}$ in June, where the indoor air velocity increased approximately linearly. However, the distribution of indoor air velocity differed slightly between cities, being higher in Hangzhou; the air velocity increased sharply from $\sim 0.8 \mathrm{~m} / \mathrm{s}$ to $>1.2 \mathrm{~m} / \mathrm{s}$ in warm conditions. According to Table 1, the annual air velocity for Hangzhou is $2.1 \mathrm{~m} / \mathrm{s}$, thus the indoor air movement may be generated by natural ventilation and the use of fans in the early summer stage. Interestingly, in mid-summer, the indoor air velocity increased for temperatures below $30^{\circ} \mathrm{C}$, but decreased significantly at higher temperatures. This trend was the clearest in Chongqing, where the air velocity increased to nearly $0.3 \mathrm{~m} / \mathrm{s}$ at $29^{\circ} \mathrm{C}$, but then decreased with increasing temperature. In midsummer, both the outdoor and indoor air temperatures are high, the cooling efficiency of ventilation and fans is limited; conversely, higher air velocities result in a warm "draught" and thermal discomfort for the occupants [42]. As a result, occupants may close windows and prefer to use air conditioners for cooling, which decreased the indoor air velocity. However, the air velocity in late summer was slightly lower than for early summer for the same indoor temperatures, except in Hangzhou. This was attributed to the previous hot experience and physiological 
acclimatisation during midsummer, which enhanced the occupants' tolerance for warmer temperatures and reduced their demands for air movement to offset thermal discomfort.

Overall, Figures 3 and 4 exhibit similar temporal distributions in different periods of the winter/summer seasons, indicating that the behavioural adaptation of occupants varies with time and climates and is influenced by their thermal experience and physiological acclimatisation.
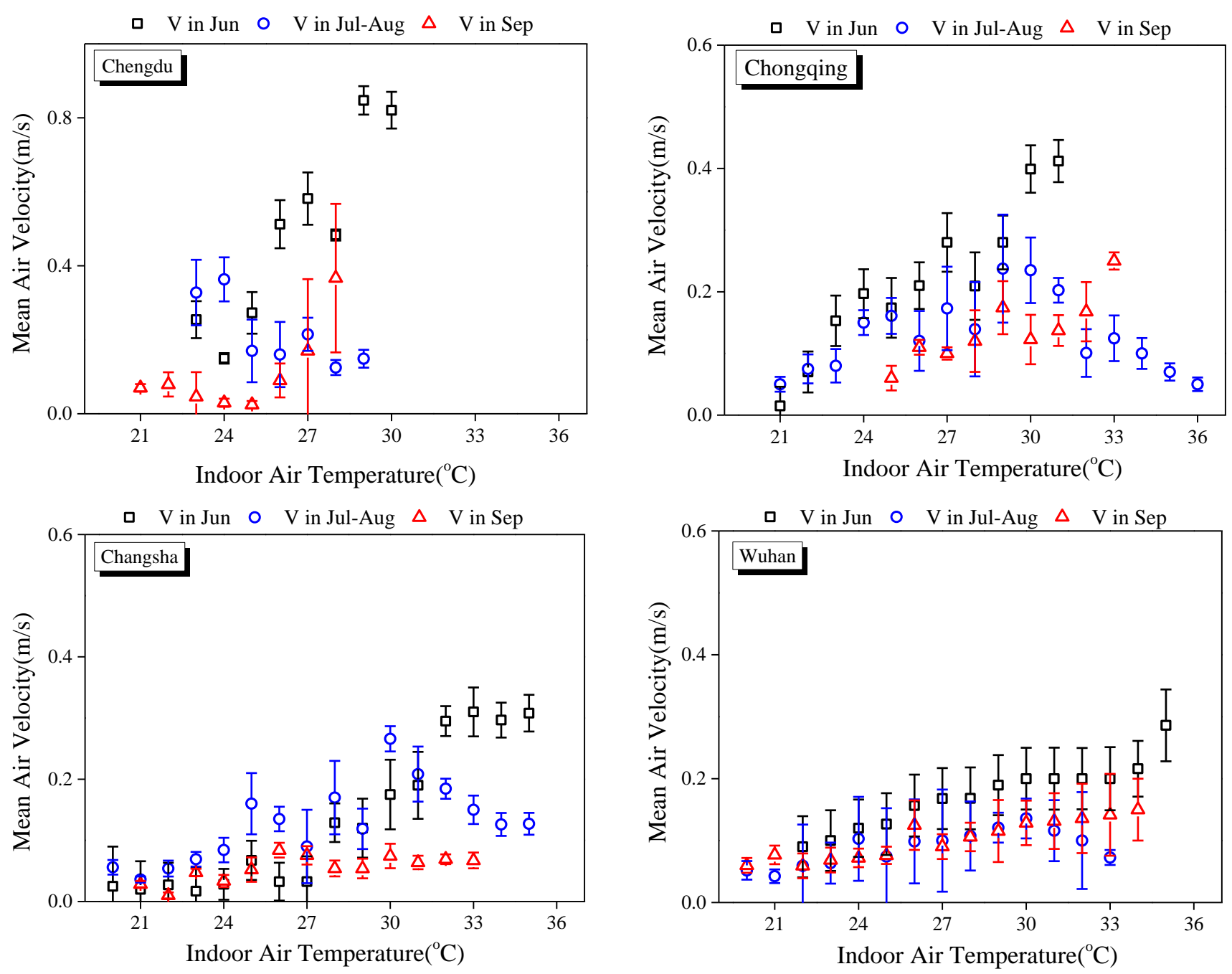

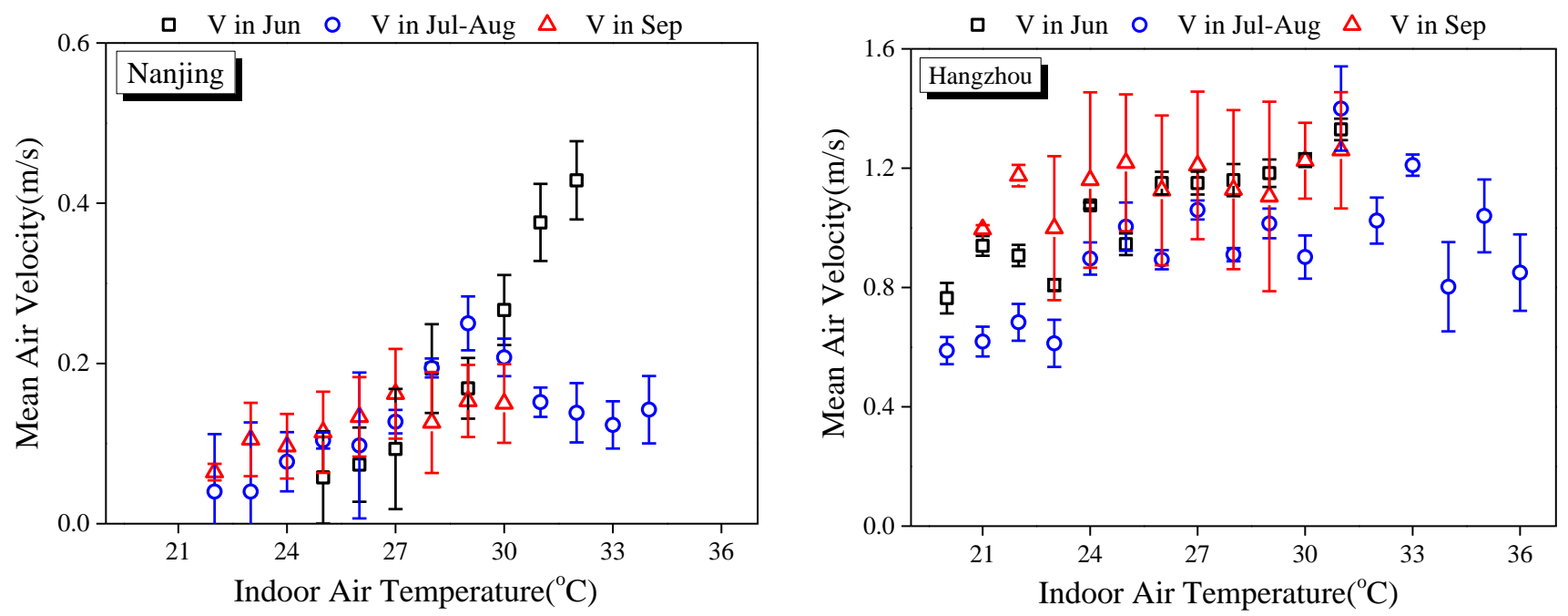

Figure 4: Indoor air velocity as a function of air temperature in different periods of summer (Jun = early summer, Jul-Aug = mid-summer, Sep = late summer).

\subsection{Variations of annual neutral temperature}

The above confirmed the dynamic adaptive variations of occupants over time, in terms of expected temperature (Figure 2), clothing adjustment (Figure 3) and air velocity regulation (Figure 4). The purpose of this study is to link the dynamic thermal adaptation to indoor thermal environment operation. All these adaptations and their levels at different times of the year would result in changes to the occupants' comfort demands; this could be reflected and quantified by the neutral temperature variations. Given this, we referred to Griffiths' method [43] to calculate the neutral temperature $T_{n}$, as shown in Eq. (3). The regression coefficient $G$, which indicates the sensitivity of the occupants' thermal sensation over a wide range of environmental temperatures, was determined to be $0.5[36,44]$.

$$
\mathrm{T}_{\mathrm{n}}=\mathrm{T}_{\mathrm{op}}-\mathrm{C} / \mathrm{G}
$$

where $\mathrm{C}$ is the thermal sensation vote using the ASHRAE 7-point scale; $\mathrm{G}=0.5^{\circ} \mathrm{C}^{-1}$ is the Griffiths constant; $\mathrm{T}_{\mathrm{op}}$ is the operative temperature (here the air temperature, ${ }^{\circ} \mathrm{C}$ ) and $\mathrm{T}_{\mathrm{n}}$ is the neutral temperature, ${ }^{\circ} \mathrm{C}$.

Using Eq. (3), the residents' personal $\mathrm{T}_{\mathrm{n}}$ values in response to the indoor temperature were calculated. Then, to address the time factor and the resulting changes in occupants' $T_{n}$, we averaged the $T_{n}$ by dates for each city. The results are displayed in 
Figure 5 in time series over a year. The grey shades mark the possible heating seasons from November to February and the cooling seasons from June to September in the HSCW zone. From Figure 5, similar change trends for residents' annual $\mathrm{T}_{\mathrm{n}}$ were found for all six cities: in the transient seasons: the $T_{c}$ of occupants increased from spring to summer and decreased from summer to autumn. In cooling seasons, however, the $T_{n}$ exhibits a trend of decreasing gradually and then increasing with time. In midsummer with high temperature, the $T_{n}$ of residents was the lowest. Such trends were also found in heating seasons: the $\mathrm{T}_{\mathrm{n}}$ in Figure 5 increased gradually from November to December. This is explainable since, over time, the outdoor temperature decreases in winter so that relying only on the thermal adaptation of residents can no longer maintain their comfort demands. In that case, the neutral temperatures increase and occupants expect to increase the indoor temperature to improve comfort. This is consistent with the expected changes in temperature with indoor annual temperatures shown in Figure 2.
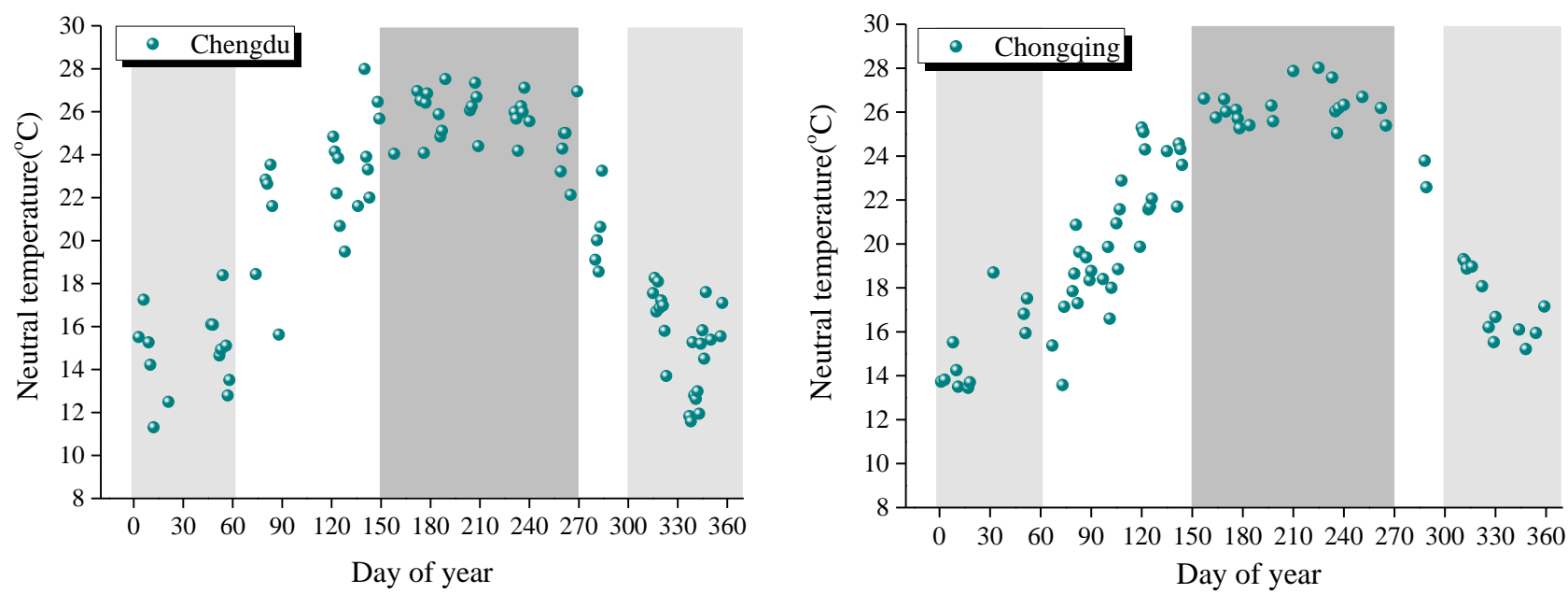

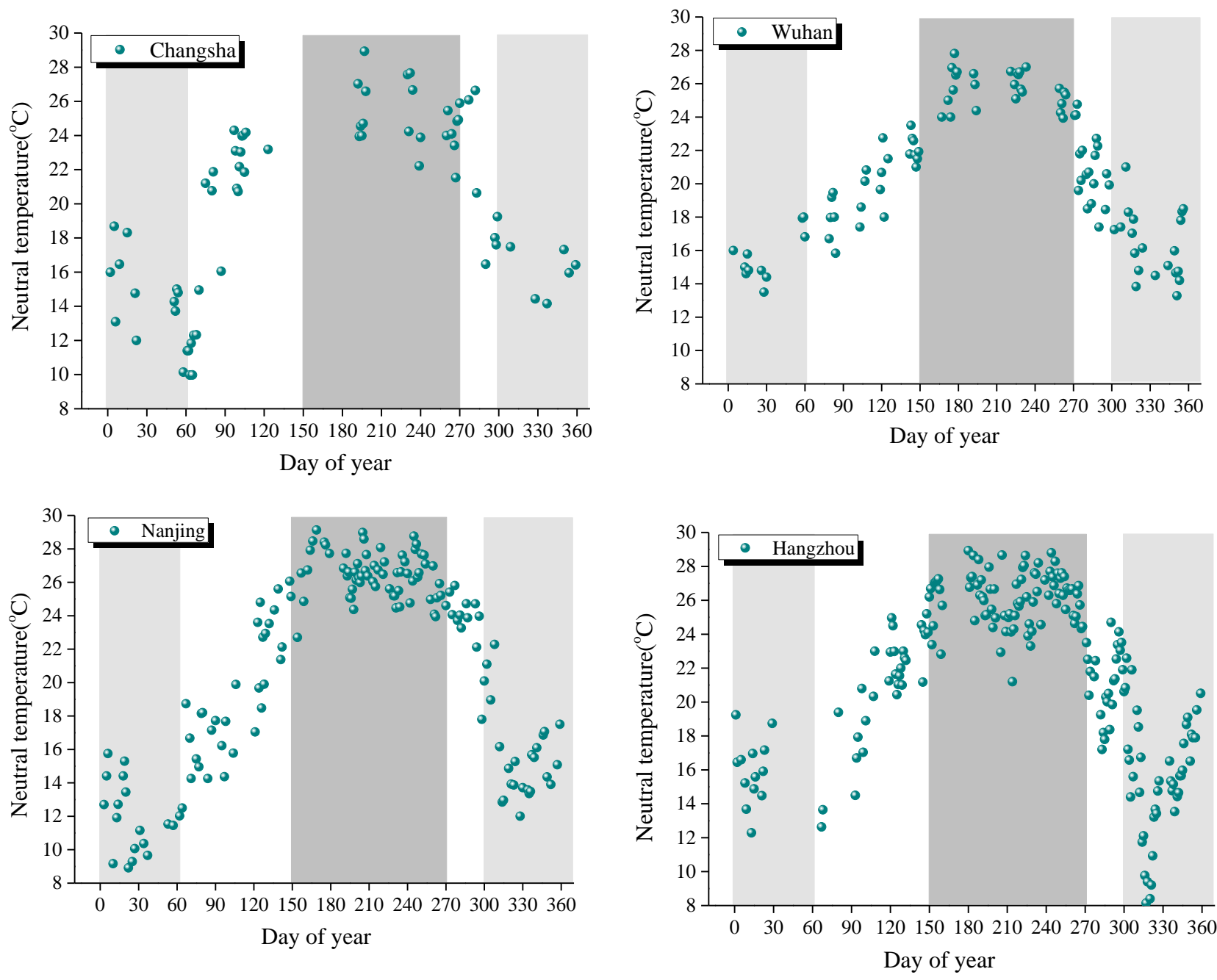

Figure 5: Neutral temperature variations over year in the six cities.

(note: the light grey shade marks the Nov, Dec, Jan, Feb in winter, and the dark grey shade marks the Jun, Jul, Aug, Sep in summer)

\subsection{Thermal-adaptation-based indoor temperature settings}

The above analysis verified the dynamic variations of occupant physiological, psychological and behavioural adaptations and their comfort demands. Based on the neutral temperatures of occupants, this section aims to design indoor thermal environments in residential buildings whilst considering dynamic thermal adaptation.

The weather data for a TMY for each city was first adopted as reference temperatures. This was for two reasons: first, though people spend nearly $90 \%$ of their time in buildings and their comfort demands may be closely related to indoor temperatures, these indoor temperatures are significantly affected by various factors, 
including the outdoor climate, building envelope performance, the occupant behaviours and their interactions with the buildings e.g. opening windows/doors. Thus, there are no representative indoor temperature data that could act as a reference in practical applications in different regions. Secondly, by contrast, the meteorological data from outdoor climates is acknowledged to reflect the local climate characteristics of an area and is commonly used in building design and energy simulation research. Moreover, the data are available for all researchers; this ensures the comparability and repeatability for different researchers. Therefore, the weather data from a TMY was adopted as the benchmark in the following analysis.

The hourly dry-bulb temperatures from the TMY were first averaged by days, i.e. outdoor daily mean air temperatures $T_{\text {out }}$, and plotted using the grey lines in Figure 6 for each city. Since the $T_{\text {out }}$ is in the form of a time series over the full year, this analysis allowed us to define a value of $16^{\circ} \mathrm{C}$ as the baseline to determine the start/end of heating in winter and a value of $26^{\circ} \mathrm{C}$ as the baseline to determine the start/end of cooling in summer. Based on these temperatures, the start/end days of heating and cooling periods were determined for the six cities (vertical dotted lines in Figure 6). Note, along with the $T_{\text {out }}$ values to determine the start/end days, we considered March $31^{\text {st }}$ as the date node denoting the last day of the heating period, unless the $\mathrm{T}_{\text {out }}$ was below $16^{\circ} \mathrm{C}$ thereafter. China standard GB 50736 [9] recommended the indoor temperature designs of $18^{\circ} \mathrm{C}-22^{\circ} \mathrm{C}$ for heating and $26^{\circ} \mathrm{C}-28^{\circ} \mathrm{C}$ for cooling (Grade II with general satisfaction) in civil buildings. With the determined start and end points, the grey shading in Figure 6 demonstrates the traditional indoor heating and cooling durations with the given temperature ranges.

Combined with Figure 5, the neutral temperature $T_{n}$, drawn using Eq. (3), was calculated as a time series and displayed as blue lines in Figure 6. Figure 6 shows the fluctuations of $T_{n}$ over time in transient seasons. Due to the moderate temperature ranges in this period, the occupant $T_{n}$ values were closely related to $T_{\text {out }}$, reflecting the occupants' dynamic thermal adaptations to temperature. In a moderate climate, as occupants can better adapt to thermal environments through using a variety of adaptive behaviours (Sections 3.3,3.4), they appropriately regulate their neutral temperatures and comfort demands (Section 3.5) with outdoor climates, as shown in Figure 6. In addition, an interesting finding in Figure 6 is that the $T_{n}$ and $T_{\text {out }}$ shared 
similar change trends while the peak and valley of the $T_{n}$ (blue lines) lagged behind that of $\mathrm{T}_{\text {out }}$. We infer that human thermal adaptation is significantly affected by previous thermal experiences not only by the outdoor climate on a particular day, but also by the climates prior to that day [17]. Hence, their comfort demands change onestep later compared to the outdoor climate.

Moreover, as addressed in Figure 5, under severe cold/hot situations in winter/summer time in the HSCW zone, neutral temperatures increase/decrease, suggesting that thermal adaptation alone is unable to meet comfort demands. Moreover, there is indeed a clear interaction between thermal adaptation and heating/cooling applications. Hence, Figure 6 further exhibits the dynamic temperature settings $\mathrm{T}_{\text {set }}$ for heating/cooling incorporating thermal adaptation changes over the seasons.

1) In the early heating period, due to the previous thermal adaptations (Figure 6), occupants have a higher tolerance for cooler environments and $T_{n}$ decreases with decreasing $\mathrm{T}_{\text {out }}$. Hence, these adaptations enable a lower temperature limit of $16^{\circ} \mathrm{C}$ [45], as shown by the red lines in Figure 6.

2) As the temperature continues to decrease in mid-winter, especially below $10{ }^{\circ} \mathrm{C}$, occupants are exposed to colder outdoor climates and adaptive behaviours can no longer offset the comfort demand provided by clothing insulation alone (Figure 3), resulting in more than $80 \%$ of people wanting higher temperatures in a building (Figure 4) as their the $T_{n}$ increases (Figure 5). Therefore, we recommend a slightly higher temperature limit of $18^{\circ} \mathrm{C}$ in mid-winter.

3) In late winter, when the outdoor temperature is increasing, behavioural regulation becomes effective again (Figure 3 ) and lower $T_{n}$ values are desired. Therefore, the lower temperature limit could be decreased to $16^{\circ} \mathrm{C}$ to make full use of clothing regulation and alleviate dependence on heating.

Similar analysis was conducted for indoor cooling temperature operation during the early, middle and late stages of summer. In Figure 6, in early summer, due to the relatively cold temperatures experienced by occupants in the spring, they exhibited greater tolerance of the increasingly warm environments. In addition, indoor air 
movement partly offsets discomfort caused by increased indoor temperatures (Figure 4). Hence, a $\mathrm{T}_{\text {set }}$ of $28^{\circ} \mathrm{C}$ is recommended as the indoor cooling setting, in order to take advantage of the adaptive regulations of the occupants. However, according to Figure $5, T_{n}$ in all six cities decreased significantly when the temperature was above $30^{\circ} \mathrm{C}$. Coupled with the reduced cooling efficiency of natural ventilation and fans [46, 47], active cooling is required in the height of summer; thus we recommend a $\mathrm{T}_{\text {set }}$ of $26^{\circ} \mathrm{C}$. In late summer, the outdoor temperature decreases and, due to the enhanced thermal tolerance of the occupants after long-term heat exposure in mid-summer, their comfort demands change, allowing the cooling temperature to be increased to $28^{\circ} \mathrm{C}$ when the $\mathrm{T}_{\text {out }}$ is below $30^{\circ} \mathrm{C}$. When the temperature falls below $26^{\circ} \mathrm{C}$, occupants adapt to indoor thermal environments using behavioural and physiological adaptations; therefore, auxiliary cooling devices are not recommended during this period. Combining these results, recommended indoor temperature settings for cooling are indicated by the solid red lines in Figure 6.

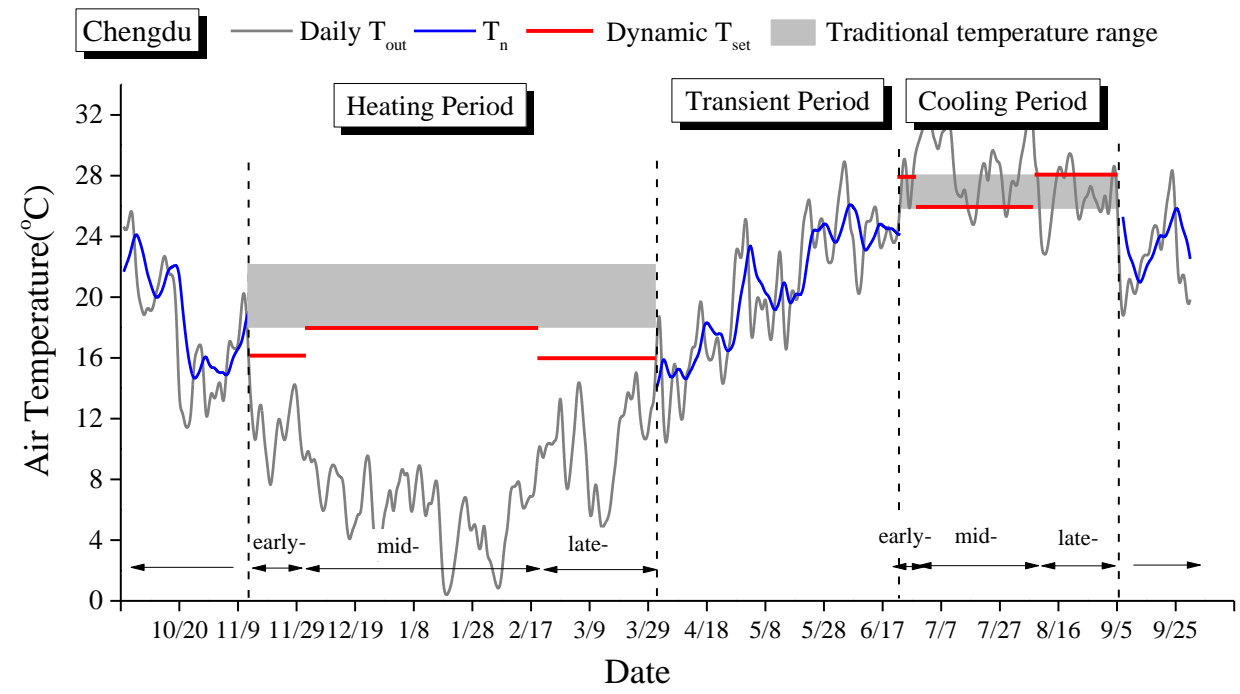



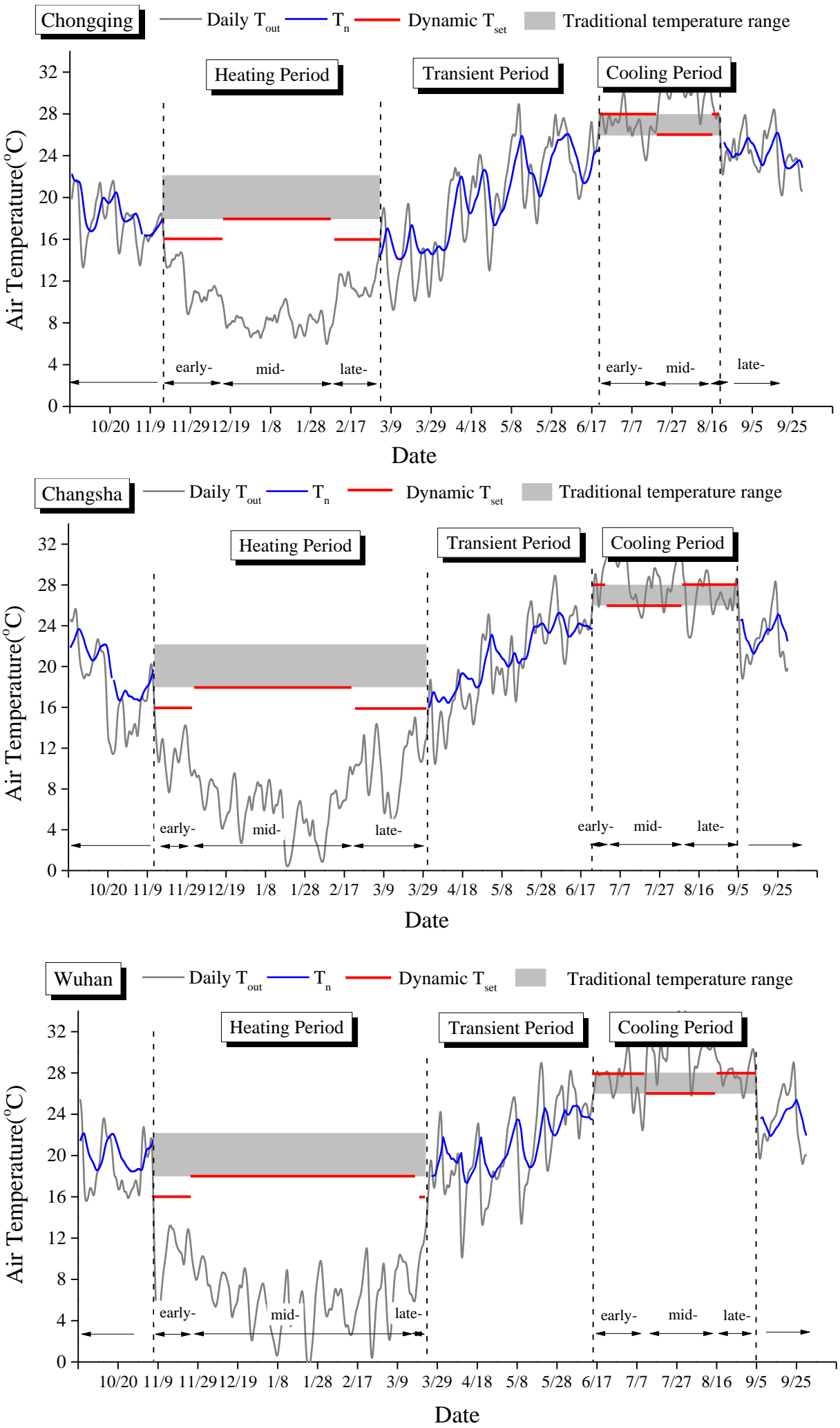

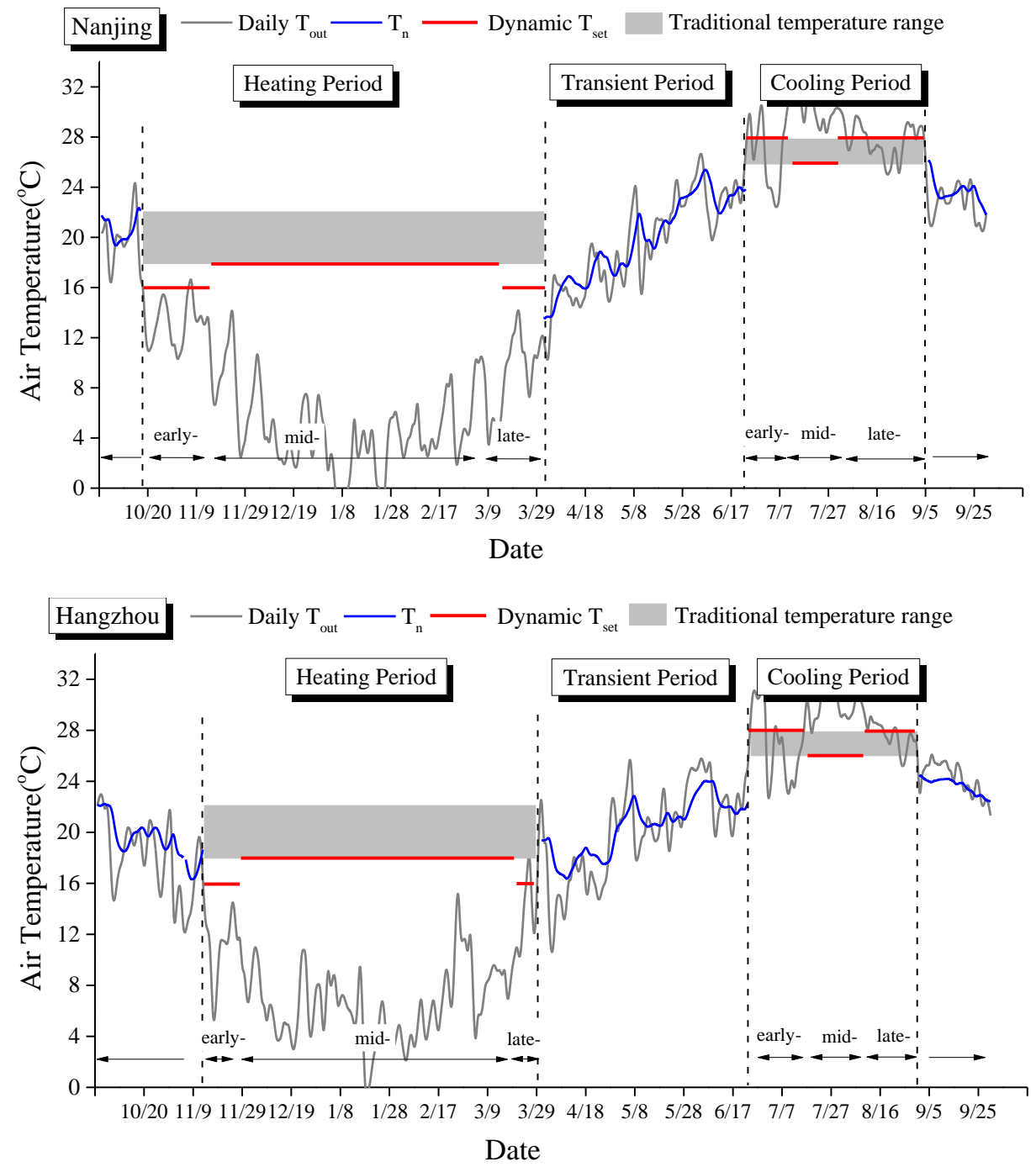

Figure 6: Annual indoor temperature operations responding to comfort demands for all six cities.

\subsection{Energy saving potential of the dynamic temperature design}

In Figure 6, we integrated the occupants' dynamic adaptations with time and quantified the heating/cooling durations and the corresponding temperature settings. The dynamic temperature setting-points show shorter heating/cooling periods than those using traditional thermostats, which allows operational flexibility for heating/cooling systems and discourages excessive energy demands. To clarify the benefits, we estimated the relative energy savings by comparing traditional thermostats and the dynamic control of temperature setting-points in these six cities. According to the start/end days (marked in black dotted lines) in Figure 6, the number of days for heating and cooling with different temperature setting-points are counted. Therefore, the relative energy saving between traditional thermostats and the dynamic 
operation of different temperature setting points is defined by Eq. (4):

$$
\begin{aligned}
& \Delta \mathrm{E}=\Delta \mathrm{E}_{\text {summer }}+\Delta \mathrm{E}_{\text {winter }} \\
& =\frac{\sum_{\mathrm{k}}^{\mathrm{M} 1+\mathrm{M} 2}\left(\mathrm{~T}_{\text {out-hourly-k}}-\mathrm{T}_{\text {standard }}\right)-\sum_{\mathrm{i}}^{\mathrm{M} 1} \mathrm{M}_{\mathrm{i}} *\left(\mathrm{~T}_{\text {out-hourly-i }}-\mathrm{T}_{\text {cool- }-1}\right)+\sum_{\mathrm{j}}^{\mathrm{M} 2} \mathrm{M}_{\mathrm{j}} *\left(\mathrm{~T}_{\text {out-hourly-j }}-\mathrm{T}_{\text {cool- }-2}\right)}{\sum_{\mathrm{k}}^{\mathrm{M} 1+\mathrm{M} 2}\left(\mathrm{~T}_{\text {out-hourly-k}}-\mathrm{T}_{\text {standard }}\right)} \\
& +\frac{\sum_{\mathrm{k}}^{\mathrm{N} 1+\mathrm{N} 2}\left(\mathrm{~T}_{\text {out-hourly-k}}-\mathrm{T}_{\text {standard }}\right)-\sum_{\mathrm{i}}^{\mathrm{N} 1} \mathrm{n}_{\mathrm{i}} *\left(\mathrm{~T}_{\text {out-hourly-i }}-\mathrm{T}_{\text {heat- }-1}\right)+\sum_{\mathrm{j}}^{\mathrm{N} 2} \mathrm{n}_{\mathrm{j}} *\left(\mathrm{~T}_{\text {out-hourly-j }}-\mathrm{T}_{\text {heat- }-2}\right)}{\sum_{\mathrm{k}}^{\mathrm{N} 1+\mathrm{N} 2}\left(\mathrm{~T}_{\text {out-hourly-k}}-\mathrm{T}_{\text {standard }}\right)}
\end{aligned}
$$

Here, $\Delta \mathrm{E}$ is the relative energy saving for heating and cooling, $\% ; \mathrm{T}_{\text {cool-1 }}$ and $\mathrm{T}_{\text {cool-2 }}$ are the temperature setting-points for cooling in this study, namely $26^{\circ} \mathrm{C}$ and $28^{\circ} \mathrm{C}$ respectively; M1 and M2 are the number of days for corresponding cooling temperature; $\mathrm{T}_{\text {heat- } 1}$ and $\mathrm{T}_{\text {heat-2 }}$ are the dynamic temperature setting-points for heating, namely $16^{\circ} \mathrm{C}$ and $18^{\circ} \mathrm{C}$ respectively; $\mathrm{N} 1$ and $\mathrm{N} 2$ are the number of days and $\mathrm{T}_{\text {out-hourly- }}$ $\mathrm{i}, \mathrm{T}_{\text {out-hourly-j, }}, \mathrm{T}_{\text {out-hourly-k }}$ are the hourly outdoor temperature in a time series of a TYM year in responding to the corresponding heating and cooling periods at $\mathrm{t}=\mathrm{i}, \mathrm{j}, \mathrm{k}$.

In Eq. (4), we assumed that when the temperature differences between the $\mathrm{T}_{\text {out- }}$ hourly and $\mathrm{T}_{\text {standard/cool/heat }}$ were $>0^{\circ} \mathrm{C}$ in summer and $<0^{\circ} \mathrm{C}$ in winter, the heating/cooling were assisted. Under this assumption, only the required values of differences between the outdoor hourly temperatures and indoor setting temperatures were summed. Then, the relative energy savings for heating and cooling in each city were calculated as shown in Figure 7. Significant energy savings were achieved by using dynamic temperature setting-points compared to the constant temperatures during the whole heating/cooling periods for all six cities. Thus, Nanjing showed the maximum energy saving potential of $\sim 34.4 \%$, followed by Chongqing, with $31.8 \%$ and Wuhan showed the smallest energy saving potential, approximately $18.9 \%$. In particular, greater energy-saving was observed for cooling in summer than for heating in winter. The maximum cooling energy saving of $29.5 \%$ was observed for Nanjing, with Wuhan showing the lowest cooling energy saving of $15.5 \%$. Since there are remarkable differences in outdoor climates between the six cities, the differences of total cooling and heating energy savings are attributed to these different climates (Table 1) and heating/cooling durations (Figure 6). Overall, Figure 7 clearly emphasises the important potential for energy savings via dynamic control of temperature setting-points throughout the cooling and heating seasons. 


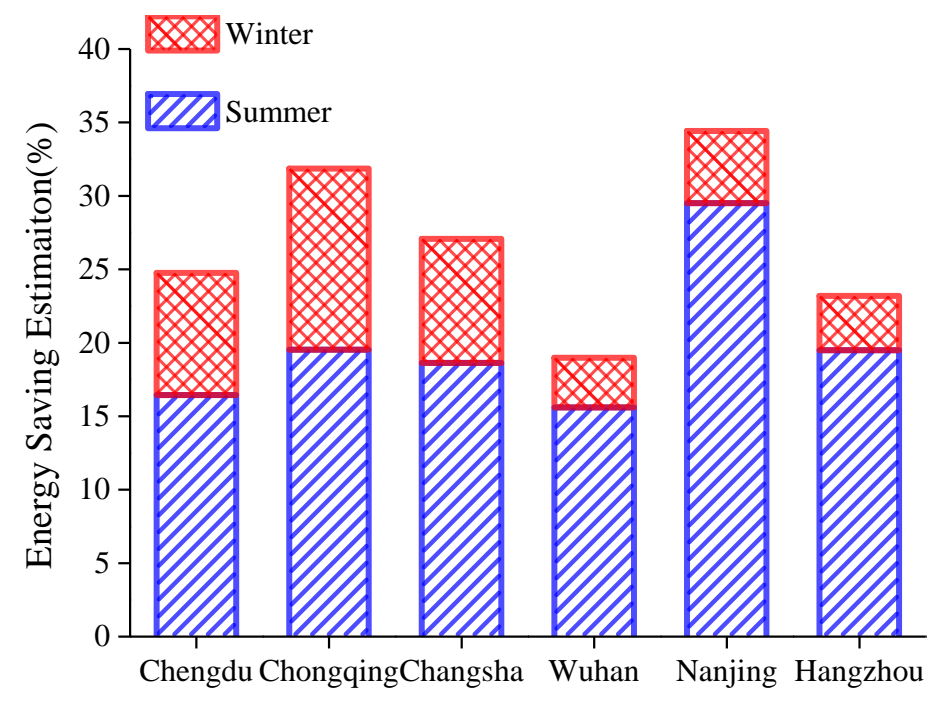

Figure 7: Relative energy savings comparing dynamic and thermostatic temperature control for heating and cooling.

\section{Discussion}

Although the Chinese standard GB 50736 [9] defines a temperature range for heating and cooling, the lower temperature limits are $26^{\circ} \mathrm{C}$ in summer and $18^{\circ} \mathrm{C}$ in winter. It is reported that indoor temperatures increase with heating going on [22]. In situations when occupants are able to regulate their behaviours to meet their comfort in the early- and late- heating/cooling seasons (Figures 3-4), such temperature limits are not overly critical and occupants could accept a wider temperature range through thermal adaptation (Figure 5). Therefore, the temperature setting recommendations in Figure 6 provide a foundation for dynamic temperature operation during the heating/cooling periods by considering the changing thermal adaptation and behaviours of occupants over time. The outcomes shorten the heating/cooling durations and decrease/increase the set temperatures; compared to the traditional reference case, this saves $\sim 34.4 \%$ of the total energy demand in Nanjing, see Figure 7 . Given that the heating/cooling to maintain thermal comfort in the building sector contributes as much as $60-70 \%$ of building energy consumption [48, 49], the above recommendations could be highly beneficial for the development of heating/cooling temperature control and operation to achieve energy savings. With increasingly updated building standards and improved building performance and insulation in 
buildings in the HSCW zone of China [50], the indoor temperatures would be less affected by outdoor climates when applying optimal passive technologies [3]. This would further extend the non-heating/cooling periods and alleviate the demands for heating/cooling devices in summer and winter [51], which can be expected to provide greater energy saving potential.

Another contribution of this study is identifying the limitations of human thermal adaptations and recommending the dynamic heating/cooling operations appropriately. At higher temperatures, occupant demands for cooling are much higher, and it is not possible to achieve comfort by adaptive mechanisms. This is also true for very low temperatures where the heating demand is too high to achieve comfort through adaptation itself [52]. However, previous adaptive models were based on the performance of naturally ventilated buildings where the running mean outdoor temperature or prevailing mean outdoor temperature range was limited to $10-30^{\circ} \mathrm{C}$ [53] or $10-33.5^{\circ} \mathrm{C}$ [8]. However, in the HSCW zone of China, due to the extreme climates, the efficacy of adjusting clothing (Figure 3) and increasing air movement (Figure 4) to improve people's personal comfort is gradually reduced with increasing temperature in summer and decreasing temperature in winter [54], resulting in converse changes in neutral temperatures under high and low temperature extremes. In such cases, assisted heating/cooling systems are necessary and a novel method for regulating temperature setting-points during heating/cooling periods is recommended in the current study (see Figure 6). This fills a gap in the current knowledge regarding support for dynamic temperature settings and operations for buildings.

The current study gives an estimation of the energy saving potential for adaptation-based temperature setting-points for heating/cooling. The relative values were based on a simplified method. As no previous research has provided accurate guidance on start/end days or durations of designed heating/cooling with demand, this study employed daily $\mathrm{T}_{\text {out }}$ from TYM data as a benchmark for determining the start/end days for heating/cooling and estimating the energy-saving potential. The designs in Figure 6 are not intended to be strictly followed by occupants, considering mixed-mode operation in residential buildings, but rather to provide guidelines for occupant behaviour when using heating/cooling devices. Future work should develop a variety of reference building models using building simulations and incorporating 
dynamic temperature settings into HVAC schedules, to enable more accurate predictions of energy savings. In addition, further studies regarding the links between human thermal adaptation and its application to heating/cooling designs in residential buildings, such as when human thermal adaptations are applicable, the degree to which the adaptations can be applied during heating/cooling seasons and when active heating/cooling technology should be applied, need real-world verification. It is highly recommended to combine longitudinal surveys with monitoring the indoor thermal environment, tracking occupant behaviour and comfort, and recording the energy demands and consumptions under different situations, in order to guide indoor temperature and heating/cooling operations with more flexibility and accuracy, to support standards, codes and policy-making in the HSCW zone.

\section{Conclusion}

This study presents the results of an in-depth analysis of variations in thermal adaptation and occupants' neutral temperatures throughout the year based on a largescale field survey in mixed-mode residential buildings in the hot summer and cold winter (HSCW) zone in China. The major conclusions are as follows:

1) Indoor temperatures were linearly related to outdoor temperatures in the moderate outdoor temperature in the range of $10-30^{\circ} \mathrm{C}$ while the natural ventilation dominated. However, this correlation was weakened outside this temperature range due to the operation of heating and cooling in the mixed-mode residential buildings.

2) Expected temperatures of residents over the year were determined using Probit models, fluctuating slightly from $22.1^{\circ} \mathrm{C}$ in Changsha to $24.4^{\circ} \mathrm{C}$ in Wuhan; this can be a general reference for effectively controlling heating/cooling usage from transient seasons to winter/summer.

3) Clothing insulation and indoor air velocity showed different variations in the early-, mid- and late- winter/summer, even for the same temperature conditions, revealing the temporal differences in occupant thermal adaptation in response to the perceived outdoor climate and thermal experience.

4) The neutral temperatures of residents increased with time going from transient 
seasons to winter and decreased from spring to midsummer, indicating that human thermal adaptation was limited for very low and very high temperatures. The start and end days for assisted cooling/heating were appropriately recommended, and the dynamic temperature settings were determined based on annual neutral temperature variations. The results provide support for incorporating human dynamic thermal adaptation with indoor temperature regulation, which is expected to aid heating/cooling operations in mixed-mode residential buildings in order to support building energy flexibility and efficiency in the HSCW zone of China.

\section{Acknowledgements}

This work is sponsored by the Ministry of Science and Technology of China Integrated Solutions for Heating and Cooling (SSHCool Project) (Grant No: 2016YFC0700301). The data analysed in this paper was from the database from a project funded by the Natural Science Foundation of China (Grant number NSFC 50838009). The completion of the paper is supported by the Fundamental Research Funds for the Central Universities in China (Grant number 2018CDJDCH0015).

\section{Declaration of interest}

None. 


\section{References:}

[1] China National Bureau of Statistics. China Statistical Yearbook, 2013. http://www.stats.gov.cn/.(In Chinese).

[2] Tsinghua University Building Energy Research Center. 2013 Annual Report on China Building Energy Efficiency. China Architecture and Building Press, Beijing, 2013. (In Chinese).

[3] Yao R, Costanzo V, Li X, Zhang Q, Li B. The effect of passive measures on thermal comfort and energy conservation. A case study of the Hot Summer and Cold Winter climate in the Yangtze River region. J Build Eng 2018; 15:298-310.

[4] Li B, Du C, Yao R, Yu W, Costanzo V. Indoor thermal environments in Chinese residential buildings responding to the diversity of climates. Appl Therm Eng 2018; 129: 693-708.

[5] Hu S, Yan D, Cui Y, Guo S. Urban residential heating in hot summer and cold winter zones of China - Status, modeling, and scenarios to 2030. Energ Policy 2016; 92: 158-170.

[6] Wang Z, de Dear RJ, Lin B, Zhu Y, Ouyang Q. Rational selection of heating temperature set points for China's hot summer-cold winter climatic region. Build Environ 2015; 93(Part 2):63-70.

[7] China State Council. National Energy Development Strategy and Action Plan for 2014 to 2020. 2014. http://www.gov.cn/zhengce/content/2014-11/19/content 9222.htm.

[8] ASHRAE 55. Thermal Environmental Conditions for Human Occupancy. In: American Society of Heating, Refrigeration, Ventilation, and Air-Conditioning. Atlanta, US, 2013.

[9] GB 50736. Design code for heating ventilation and air conditioning of civil buildings. In: Ministry of Housing and Urban Rural Development. Beijing, China, 2012.

[10] Yao R, Liu J, Li B. Occupants' adaptive responses and perception of thermal environment in naturally conditioned university classrooms. Appl Energ 2010; 87(3):1015-1022.

[11] Li B, Tan M, Liu H, Ma X, Zhang W. Occupant's perception and preference of thermal environment in free-running buildings in China. Indoor Built Environ 2010; 19(4):405-412.

[12] Brager GS, Borgeson S, Lee Y. Control strategies for mixed-mode buildings. Retrieved from Center for the Built Environment, C Berkeley, 2007. https://escholarship.org/uc/item/8kp8352h.

[13] Luo M, Cao B, Damiens J, Lin B, Zhu Y. Evaluating thermal comfort in mixed-mode buildings: A field study in a subtropical climate. Build Environ 2015; 88: 46-54.

[14] De Vecchi R, Candido C, de Dear RJ, Lamberts R. Thermal comfort in office buildings: Findings from a field study in mixed-mode and fully-air conditioning environments under humid subtropical conditions. Build Environ 2017;123: 672-683.

[15] Damiati SA, Zaki SA, Rijal HB, Wonorahardjo S. Field study on adaptive thermal comfort in office buildings in Malaysia, Indonesia, Singapore, and Japan during hot and humid season. Build Environ 2016;109: 208-223.

[16] Humphreys MA, Rijal HB. Examining and developing the adaptive relation between climate and thermal comfort indoors. Proceedings of Conference: Adapting to Change: New Thinking on Comfort Cumberland Lodge, Windsor, 2010.

[17] Yan H, Yang L, Zheng W, Li D. Influence of outdoor temperature on the indoor environment and thermal adaptation in Chinese residential buildings during the heating season. Energ Build 2016; 
116:133-140.

[18] Liu J, Yao R, McCloy R. An investigation of thermal comfort adaptation behaviour in office buildings in the UK. Indoor Built Environ 2013; 23:675-691.

[19] Yao R, Li B, Liu J. A theoretical adaptive model of thermal comfort- Adaptive Predicted Mean Vote (aPMV). Build Environ 2009; 44:2089-2096.

[20] Liu H, Wu Y, Li B, Cheng Y, Yao R. Seasonal variation of thermal sensations in residential buildings in the Hot Summer and Cold Winter zone of China. Energ Build 2017; 140: 9-18.

[21] Rijal HB, Honjo M, Kobayashi R, Nakaya T. Investigation of comfort temperature, adaptive model and the window-opening behaviour in Japanese houses. Archit Sci Rev. 2013; 56:54-69.

[22] Wang Z, Ji Y, Ren J. Thermal adaptation in overheated residential buildings in severe cold area in China. Energ Build 2017; 146(7):322-332.

[23] Zhang Y, Chen H, Wang J, Meng Q. Thermal comfort of people in the hot and humid area of Chinaimpacts of season, climate, and thermal history. Indoor Air 2016; 26(5): 820-830.

[24] Lee JB, Kim TW, Min YK, Yang HM. Seasonal acclimatization in summer versus winter to changes in the sweating response during passive heating in Korean young adult men. Korean J Physiol Pharmacol 2015; 19(1)9-14.

[25] Umemiya N. Seasonal variations of physiological characteristics and thermal sensation under identical thermal conditions. J Physiol Anthropol 2006; 25: 29-39.

[26] Aghniaey S, Lawrence TM. The impact of increased cooling setpoint temperature during demand response events on occupant thermal comfort in commercial buildings: A review. Energ Build 2018;173:19-27.

[27] Hong T, Kim J, Lee M. A multi-objective optimization model for determining the building design and occupant behaviors based on energy, economic, and environmental performance. Energ 2019; 174:823-834.

[28] Wu Z, Li N, Wargocki P, Peng J, Li J, Cui H. Field study on thermal comfort and energy saving potential in 11 split air-conditioned office buildings in Changsha, China. Energy 2019; 182:471-482.

[29] Zhang Y, Mai J, Zhang M, Wang F, Zhai Y. Adaptation-based indoor environment control in a hothumid area. Build Environ 2017; 117:238-247.

[30] ISO 7726 Ergonomics of the thermal environment-Instruments for measuring physical quantities. In: International Organization for Standardization, 2001.

[31] Li B, Yao R, Wang Q, Pan Y. An introduction to the Chinese Evaluation Standard for the indoor thermal environment. Energ Build 2014; 82:27-36.

[32] Xiong J, Yao R, Grimmond S, Zhang Q, Li B. A hierarchical climatic zoning method for energy efficient building design applied in the region with diverse climate characteristics. Energ Build 2019; 186:355-367.

[33] Chen $\mathrm{J}$ and Cheng C. Extracting classification rule of software diagnosis using modified MEPA. Expert Syst Appl 2008; 34:411-418.

[34] ISO 9920 Ergonomics of the thermal environment - Estimation of thermal insulation and water vapour resistance of a clothing ensemble. In: International Organization for Standardization, 9920, 2007.

[35] Singh MK, Mahapatra Sadhan, Atreya SK. Adaptive thermal comfort model for different climatic 
zones of North-East India. Appl Energ 2011; 88:2420-2428.

[36] Nicol JF, Humphreys MA. Derivation of the adaptive equations for thermal comfort in free-running buildings in European standard EN15251. Build Environ 2010; 45:11-17.

[37] Yan H, Mao Y, Yang L. Thermal adaptive models in the residential buildings in different climate zones of Eastern China. Energ Build 2017; 141:28-38.

[38] de Dear RJ. Developing an adaptive model of thermal comfort and preference. ASHRAE Trans 1998; 104:73-81.

[39] Ballantyne ER, Hill RK, Spencer JW. Probit analysis of thermal sensation assessments. Int J Biometeorol 1977; 21:29-43.

[40] Jiao Y, Yu H, Wang T, An Y, Yu Y. Thermal comfort and adaptation of the elderly in free-running environments in Shanghai, China. Build Environ 2017; 118:259-272.

[41] Liu W, Zheng Y, Deng Q, Yang L. Human thermal adaptive behaviour in naturally ventilated offices for different outdoor air temperatures: A case study in Changsha China. Build Environ 2012; 50:76-89.

[42] Du C, Li B, Liu H, Wei Y, Tan M. Quantifying the cooling efficiency of air velocity by heat loss from skin surface in warm and hot environments. Build Environ 2018; 136:146-155.

[43] Griffths I. Thermal comfort studies in buildings with passive solar features. Commission of the European Community. UK, 1990.

[44] Humphreys MA, Nicol JF, Raja IA. Field Studies of Indoor Thermal Comfort and the Progress of the Adaptive Approach. Adv Build Energ Res 2007; 1:55-88.

[45] Wang Z, Zhang L, Zhao J, He Y, Li A. Thermal responses to different residential environments in Harbin. Build Environ 2011; 46(11):2170-2178.

[46] Liu W, Yang D, Shen X, Yang P. Indoor clothing insulation and thermal history: A clothing model based on logistic function and running mean outdoor temperature. Build Environ 2018; 135:142-152.

[47] Zhang H, Arens E, Zhai Y. A review of the corrective power of personal comfort systems in nonneutral ambient environments. Build Environ 2015; 91:15-41.

[48] Anderson JE, Wulfhorst G, Lang W. Energy analysis of the built environment - A review and outlook. Renew Sust Energ Rev 2015; 44:149-158.

[49] Liu D, Zhao F, Tang G. Active low-grade energy recovery potential for building energy conservation. Renew Sust Energ Rev 2010; 14(9):2736-2747.

[50] McNeil MA, Feng W, Can SDLR, Khanna NZ, Ke J, Zhou N. Energy efficiency outlook in China's urban buildings sector through 2030. Energy Policy 2016; 97:532-539.

[51] Short CA, Yao R, Luo G, Li B. Exploiting a Hybrid Environmental Design Strategy in the Continental Climate of Beijing. Int J Vent 2012; 11:105-130.

[52] Takasu M, Ooka R, Rijal HB, Indraganti M, Singh MK. Study on adaptive thermal comfort in Japanese offices under various operation modes. Build Environ 2017; 118:273-288.

[53] pr EN 16978-1. Energy Performance of Buildings - Part 1: Indoor Environmental Input Parameters for Design and Assessment of Energy Performance of Buildings Addressing Indoor Air Quality, Thermal Environment, Lighting and Acoustics-Module M1-6. In: Brussels Technical Committee, 2015.

[54] de Dear RJ, Kim J, Parkinson T. Residential adaptive comfort in a humid subtropical climate- 
Sydney Australia. Energ Build 2018; 158:1296-1305. 